\title{
ACTUALIZACIONES
}

\section{LA BIOPSIA DE PIEL}

GERZAIN RODRIGUEZ TORO*, FELIPE JARAMILLO**, JUAN GUILLERMO CHALELA***

\section{INTRODUCCION}

La primera biopsia de piel podría atribuírsele a Marcello Malpighi (1628-1690), fundador de la anatomía microscópica, quien describió con un microscopio rudimentario el estrato de la piel que lleva su nombre ${ }^{(1)}$. El primer texto de dermatopatología no apareció sino hasta 1840 , escrito por Gustav Simon, considerado como el padre de la patología cutánea ${ }^{(2)}$.

La biopsia de piel se volvió un procedimiento corriente a partir de finales del siglo pasado y comienzos del presente, cuando investigadores como Unna, Gans, F. y H. Pinkus, Darier y Brocq entre otros, empezaron a complementar la descripción clínica de lesiones dermatológicas con un análisis histológico de las mismas ${ }^{(3,4)}$.

Con excepción de la sangre, ningún otro tejido humano vivo puede obtenerse tan fácilmente para su estudio microscópico como la piel. Las enfermedades cutáneas se observan directamente y las biopsias se podrían tomar en todos los estadios de la enfermedad, sin detrimento del estado general del paciente. El espécimen obtenido proporciona información útil no sólo sobre la entidad cutánea, sino que puede constituír una manera rápida, simple y poco invasiva de diagnosticar una enfermedad sistémica.

La biopsia de un nódulo cutáneo de un carcinoma metastásico puede evitar una cirugía abdominal ${ }^{(5)}$, o conducir al diagnóstico de una cisticercosis del sistema nervioso central (Fig. 1) o de una amiloidosis primaria sistémica (Figs. 2-3). Una imagen de vasculitis cutánea séptica puede sugerir el diagnóstico de endocarditis bacteriana. La biopsia de piel también puede cues- tionar y reorientar un resultado de laboratorio aparentemente inobjetable ${ }^{(6)}$, o llevar al diagnóstico de glucagonoma pancreático ${ }^{(7)}$.

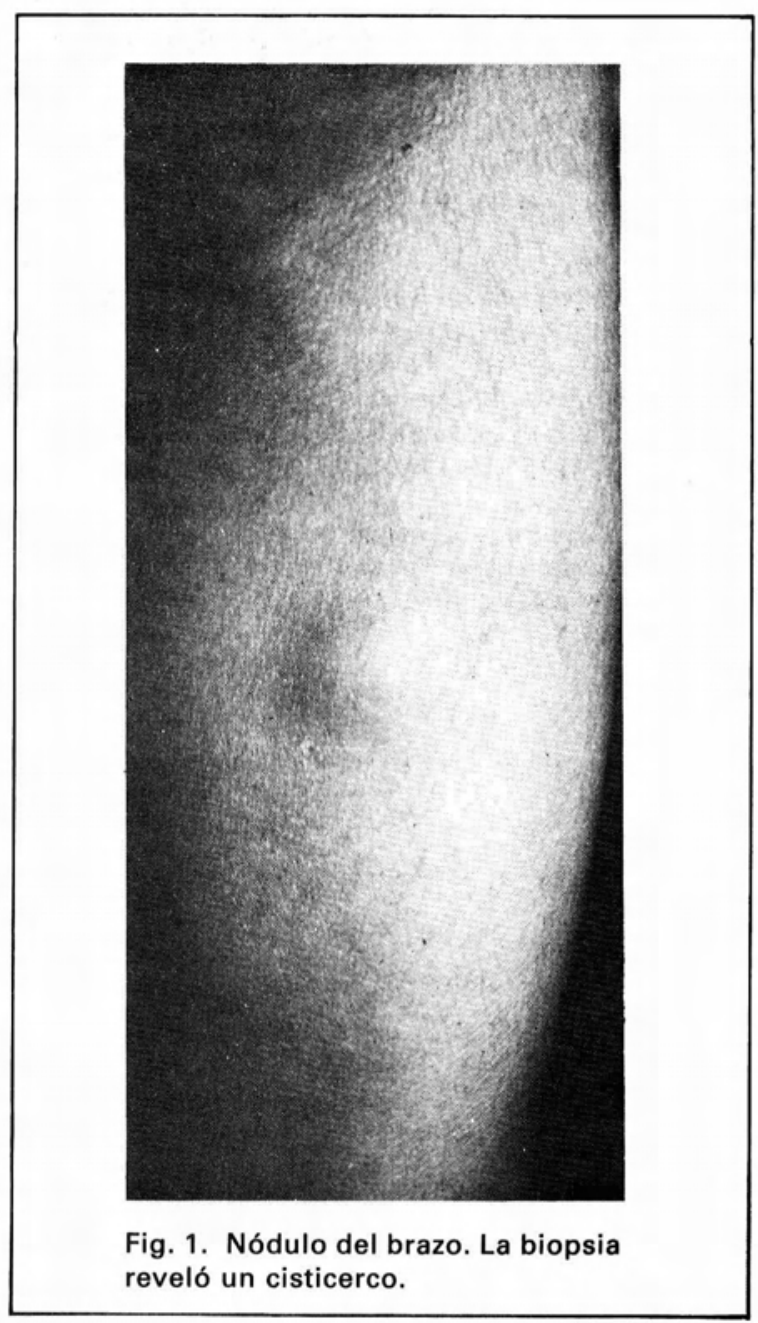

* Jefe del Grupo de Patología del Instituto Nacional de Salud. Bogotá. Profesor Asociado de Cátedra, Facultad de Medicina. U. N.

*** Jefe del Servicio de Dermatología del Hospital Militar Central. Bogotá. 


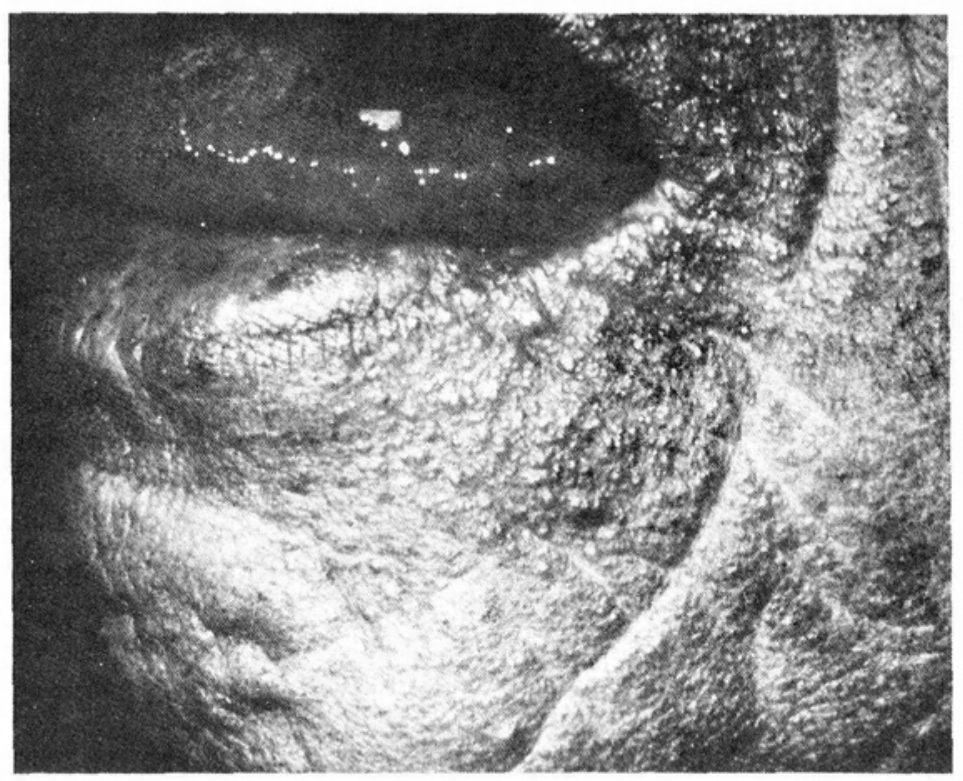

Figs. 2-3. Pápulas translúcidas en una mujer con amiloidosis primaria sistémica. La biopsia de una pápula (Fig. 3) muestra depósitos de amiloide sub-epidérmicos $y$ alrededor de los vasos en la dermis profunda, Fig. 3 Rojo Congo. 160X.

El estudio de biopsias sucesivas en la evolución de una dermatosis ha permitido conocer en detalle el proceso patogénico de algunas enfermedades cutáneas. La biopsia de piel es de mucha utlidad en la evaluación de diversas medidas terapéuticas ${ }^{(3)}$.

Pocas enfermedades cutáneas presentan un cuadro histológico característico con excepción de los tumores de piel $^{(3)}$. Por esta razón, el clínico debe suministrar datos del paciente, como sexo, edad, sitio de la biopsia, evolución y aspecto de las lesiones para que el patólogo pueda llegar a un diagnóstico más preciso. Ante una entidad dermatológica difícil, el médico no dermatólogo posiblemente se beneficiaría más de una interconsulta con un dermatólogo que de la biopsia ${ }^{(8)}$, puesto que éste al examinar un paciente, está practicando un estudio patológico macroscópico de toda la superficie cutánea. Los datos pertinentes de este examen deben comunicarse al patólogo que basa su diagnóstico no sólo en la imagen macroscópica sino en la correlación clínico-patológica o sea en el análisis conjunto de los hallazgos macro y microscópicos. La posesión de un microscopio no dota al patólogo de poderes sobrenaturales ni de infalibilidad ${ }^{(9)}$, concepto ya enfatizado por Virchow en sus embates contra la biop$\operatorname{sia}^{(10)}$.

La dificultad del patólogo general para interpretar la biopsia de piel proviene en gran parte de su poca

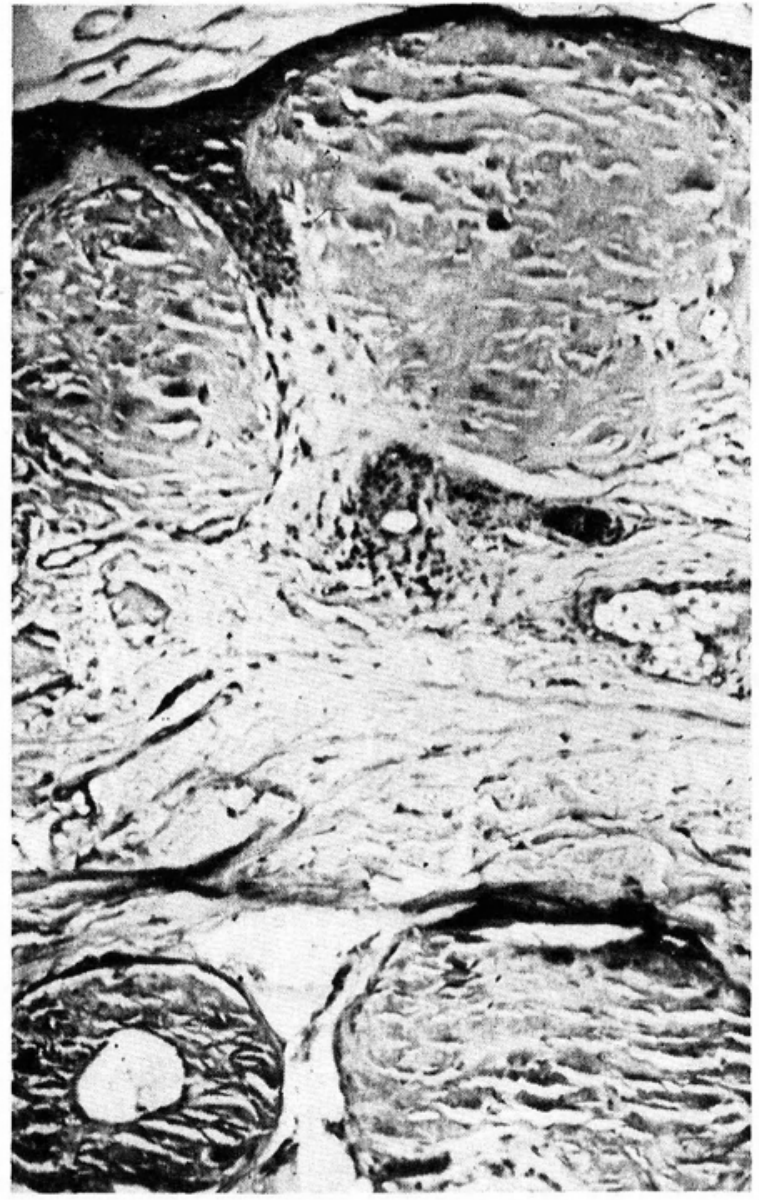

Fig. 3. 
familiaridad con la patología cutánea macroscópica. La incursión cada vez más frecuente del dermatólogo en la dermatopatología se debe a su amplio conocimiento del aspecto macroscópico de las lesiones de la piel.

La dermatopatología es una especialidad de origen reciente, para patólogos y dermatólogos, en la que es esencial el conocimiento conjunto clínico e histopatológico general ${ }^{(4)}$.

El estudio de la biopsia de piel es tan complejo y amplio, que dieciocho artículos en dos números de la revista "Cutis", con el ilustre investigador Hermann Pinkus como editor invitado, se dedicaron al análisis de la patología cutánea de diversos patrones morfológicos, entidades y lesiones ${ }^{(11,12)} *$.

\section{INDICACIONES:}

En general, una biopsia sirve para obtener información sobre la naturaleza y extensión de la enfermedad en el tejido que se examina ${ }^{(10)}$.

La biopsia cutánea es un procedimiento simple que se puede hacer en un consultorio. Está indicada cuando existe alguna duda acerca del diagnóstico clínico; es obligatoria si se sospecha una neoplasia ${ }^{(13)}$, benigna o maligna (Figs. 4-7). Se realiza con fines diagnósti$\cos$, terapéuticos, investigativos o docentes. El paciente debería ser informado del propósito con el cual se le toma la muestra y, cuando se trate de los dos últimos mencionados, no debe representarle costo alguno. Prácticamente no tiene ninguna contraindicación. Se le consideraba improcedente en casos sospe-

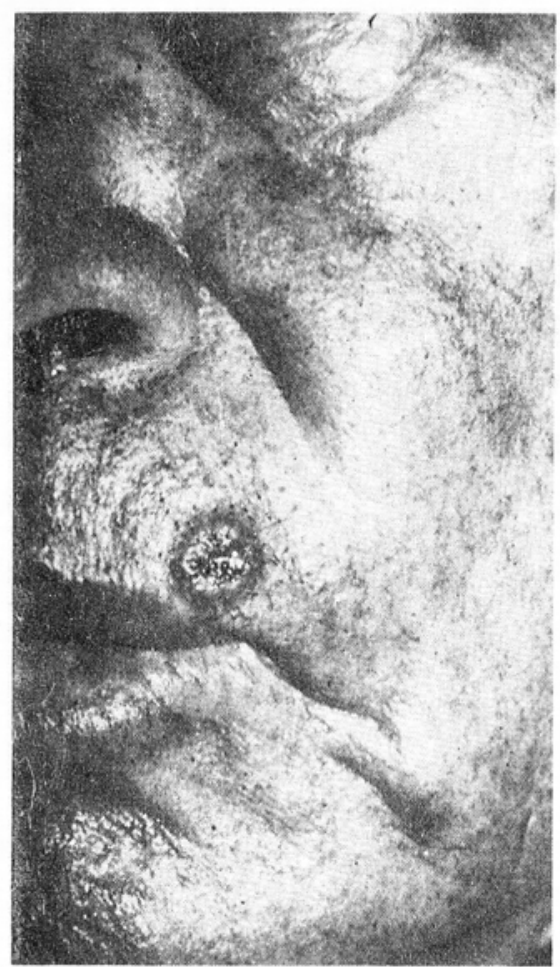

Fig. 4.

"Un libro bien ilustrado, "Fundamentals of skin biopsy". Year Book Medical Publishers, Co. Chicago, 1986, escrito por la doctora June K. Robinson, profesora de Dermatología y Cirugía de Northwestern University, incluye excelentes aspectos prácticos sobre la biopsia cutánea, tales como las indicaciones, técnicas, cuidados de la herida, complicaciones, instrumentos y mejoramiento cosmético.

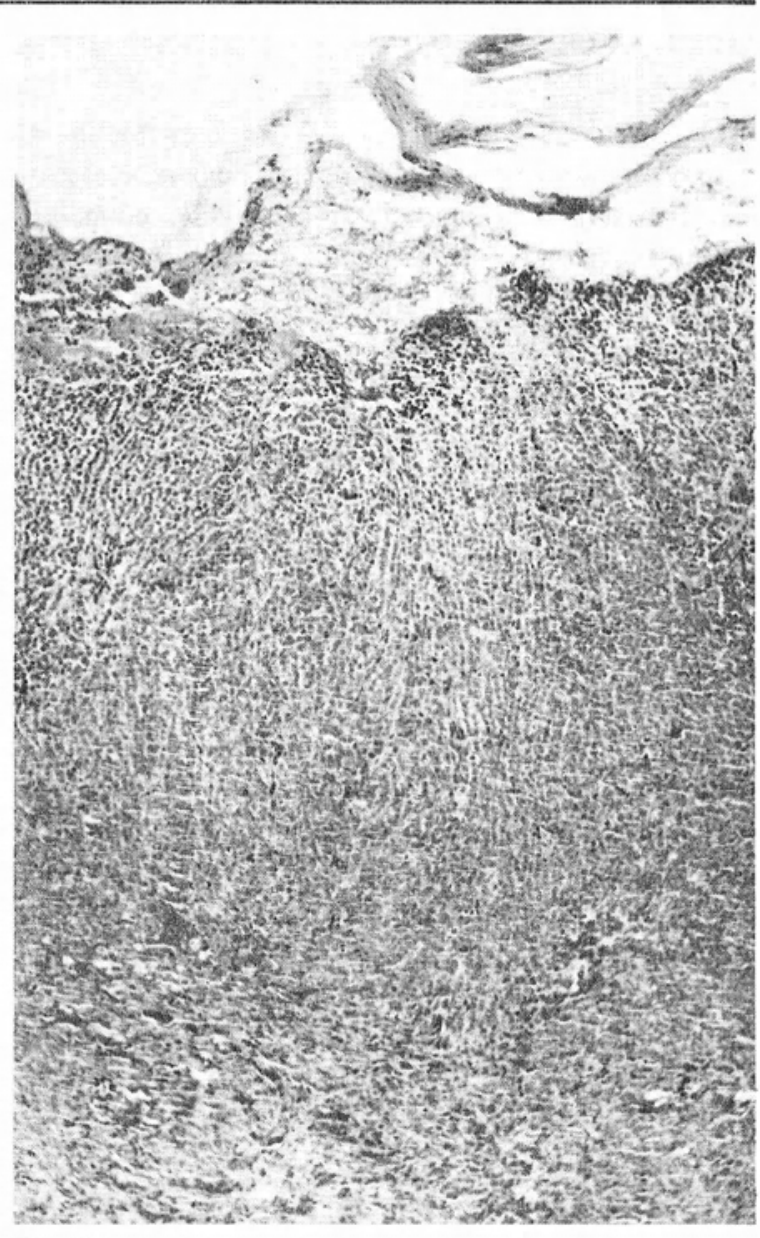

Fig. 5. 
Fig. 6.
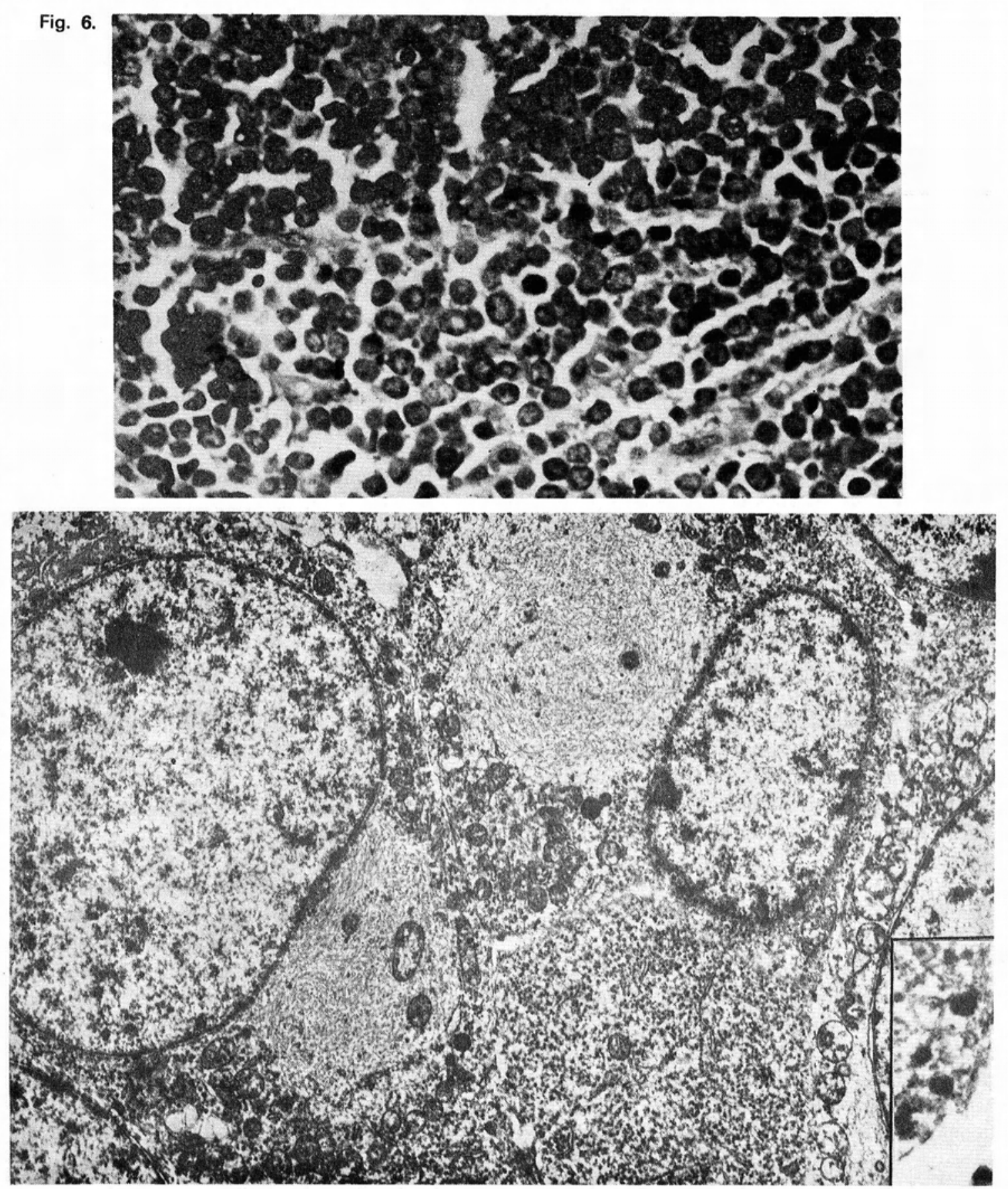

Figs. 4-7. Pequeño tumor ulcerado en un hombre de 72 años, que sugiere un carcinoma basocelular. La biopsia demostró un tumor de células pequeñas (Figs. 5-6), trabecular, que se interpretó como tumor de células de Merkel, sospecha que se confirmó con el estudio de microscopía electrónica (Fig. 7), en el cual se ven células con eucromatina, nucléolos pequeños, abundantes ribosomas, acúmulos de filamentos intermedios paranucleares y gránulos neurosecretorios, que se destacan en el recuadro. Fig. 5 HE 40 X; Fig. 6 HE 400 X. Fig. 77000 X. Recuadro: 29.000 X. 
chosos de melanoma, por el riesgo de facilitar la diseminación tumoral, temor que ya ha sido desvirtuado ${ }^{(5}$, 14). En pacientes anticuagulados la biopsia cutánea puede tomarse con las precauciones necesarias.

Sólo es posible obtener información valiosa de la biopsia cuando se ha realizado luego de un análisis clínico apropiado. La selección de la muestra es esencial para que pueda responder a los interrogantes del clínico. Debe tomarla el médico tratante y no el cirujano ${ }^{(9,13)}$. Otros métodos útiles en el diagnóstico, como el examen directo de escamas con hidróxido de potasio, no deben ser reemplazados por la biopsia ${ }^{(8)}$.

Cuando el resultado de una biopsia ayuda a tomar una decisión con respecto al paciente, se puede decir que "perfeccionó" el diagnóstico o que aumentó la "información total útil" del mismo; en este sentido es posible cuantificar "el contenido de información" de una biopsia ${ }^{(8)}$. Anderson ${ }^{(8)}$ revisó la experiencia de un año para establecer si la biopsia de piel había perfeccionado o mejorado el diagnóstico clínico y encontró que el $75 \%$ de todos los informes de patología confirmaban o aportaban información nueva o útil, y que cerca de la cuarta parte suministraban menos información de la que el clínico tenía; en $2 \%$ de los casos el informe era engañoso. Un análisis semejante de 469 biopsias nuestras, nos demostró que el diagnóstico clínico se confirmó en el $65 \%$, se hizo un diagnóstico diferente que modificó el manejo general del paciente en el $33 \%$ de los casos y en el $2 \%$ fue de utilidad dudosa.

\section{SITIO DE LA BIOPSIA:}

La selección del sitio para la toma de la muestra dependerá del diagnóstico sospechado. Las consideraciones cosméticas aunque importantes, deberán ser secundarias ${ }^{(15)}$. Toda biopsia cutánea deja cicatriz. Es preferible un diagnóstico histopatológico preciso con una cicatriz aceptable, que una cicatriz mínima con material insuficiente para su estudio histológico ${ }^{(5)}$.

Las siguientes pautas generales se deben tener en

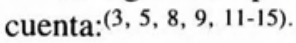

1. Use sacabocados de $3 \mathrm{~mm}$ o mayores, o bisturí. Siempre trate de incluir hipodermis. Si las lesiones clínicas son polimorfas, no dude en tomar dos o más biopsias.
2. La biopsia debe ser tomada por el dermatólogo o médico a cargo del paciente. Si se le remite para ser intervenido por el cirujano, debe llevar claramente delimitada la lesión cutánea de donde se va a tomar la biopsia.

3. En las enfermedades eritemato-escamosas como el liquen plano y la psoriasis y en las enfermedades granulomatosas como micobacteriosis, sarcoidosis y micosis subcutáneas, la biopsia se debe obtener del centro de una lesión madura, plenamente establecida.

4. En placas mayores de $3 \mathrm{~cm}$ de diámetro y en lesiones anulares como el granuloma anular, el eritema figurado y el multiforme, la biopsia se debe tomar del borde activo de la lesión.

5. En las enfermedades ampollosas se debe escoger la lesión más reciente posible ${ }^{(16)}$, de pocas horas de evolución. La vesícula o ampolla debe preservarse al máximo, pues el análisis de su base y del epitelio que la recubre es esencial para el diagnóstico (Figs. $8-9)$. En las epidermolisis ampollosas, si no hay lesiones recientes, se traumatiza ligeramente un área cutánea y de allí se toma la biopsia.

6. Cuando se sospeche lepra, la biopsia debe ser incisional y profunda, tomando más de $8 \mathrm{~mm}$ de la unión dermohipodérmica, sitio donde se pueden visualizar mejor los nervios y anexos afectados por la enfermedad. (Figs. 10-11).

7. En las enfermedades del tejido conjuntivo (lupus eritematoso, morfea, esclerodermia, escleredema, dermatomiositis) y en las enfermedades caracterizadas por nódulos, debe tomarse una biopsia profunda con amplio contenido hipodérmico. Debe hacerse con bisturí o con "punch" de $8 \mathrm{~mm}$. En los nódulos de la hipodermitis es mandatoria la biopsia escisional, con bisturí, tomando numerosos lobulillos adiposos. La biopsia con sacabocados no es útil en las hipodermitis (Figs. 12-13).

La biopsia de piel y músculo con diagnóstico de "colagenosis" en nuestra experiencia es normal en más del $90 \%$ de los casos. Quizás falla el análisis macroscópico. Si la piel es normal a la inspección, igual será la biopsia. Cuando se sospeche lupus eritematoso sistémico, la prueba de la banda lúpica con IFD tiene alta sensibilidad en la piel indemne ex- 


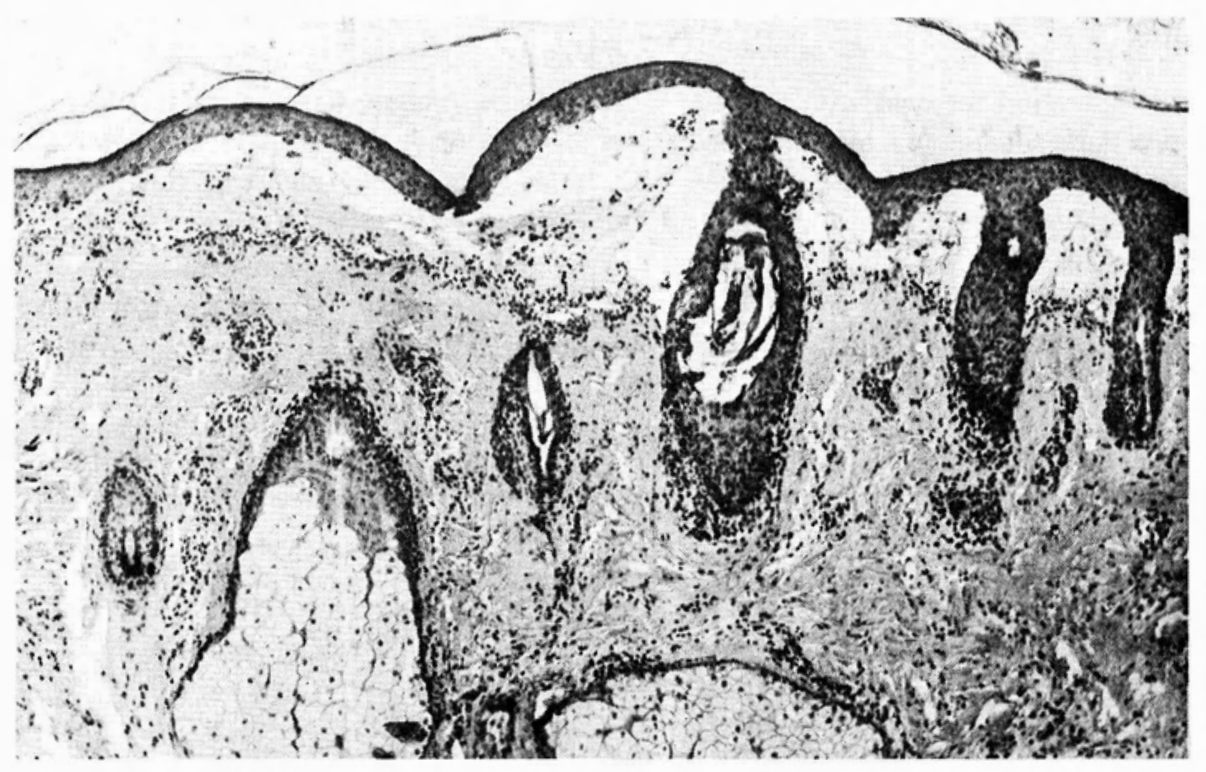

Fig. 8. Ampolla subepidérmica cubierta por epitelio intacto. Microabscesos en las papilas y también alrededor de los anexos. La biopsia adecuada permite el diagnóstico de enfermedad de Duhring. HE $160 \mathrm{X}$.

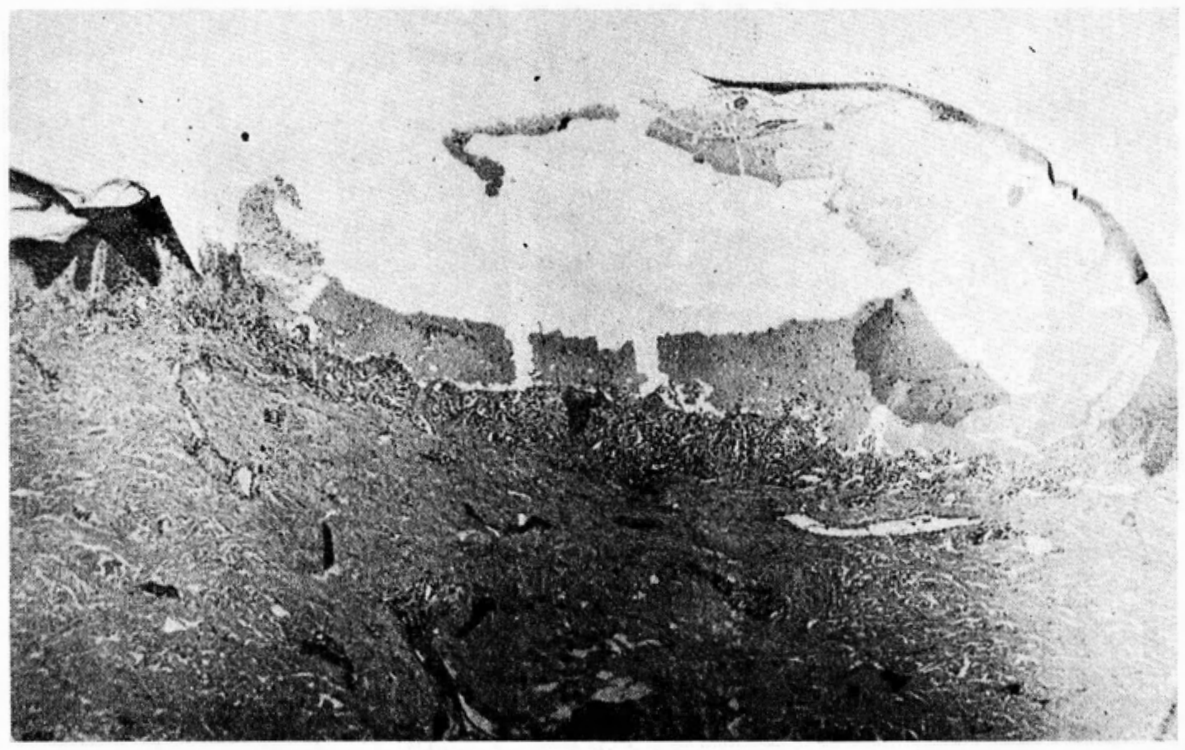

Fig. 9. Ampolla desgarrada. Cuando esto sucede, bien sea en la toma de la biopsia, especialmente si se usa "punch", o durante el corte en el micrótomo, la interpretación de la imagen es imposible. HE $63 \mathrm{X}$. 
puesta al sol. La sensibilidad disminuye y la especificidad aumenta cuando se hace en piel sana no expuesta al $\operatorname{sol}^{(5)}$.

8. Toda úlcera de aparición reciente, con más de 15 días de evolución debe someterse a biopsia, principalmente para descartar un tumor. Entre nosotros esta biopsia es útil para diagnosticar leishmaniasis y paracoccidioidomicosis. Está indicada en úlceras de vieja data sobre terreno varicoso por su eventual degeneración maligna.
9. Muchos pacientes son renuentes a permitir la biopsia de la cara. Es posible obtener una muestra adecuada de una lesión retroauricular, en el borde del cuero cabelludo, o debajo del mentón ${ }^{(13)}$ o siguiendo un pliegue fisiológico, donde una pequeña cicatriz no se ve fácilmente. Algunos desaconsejan la biopsia de lesiones ulceradas de leishmaniasis cutáneas de la cara, especialmente en niños. En nuestra experiencia la biopsia de estas lesiones ni agrava ni extiende el proceso y sí puede ser beneficiosa en el diagnóstico.

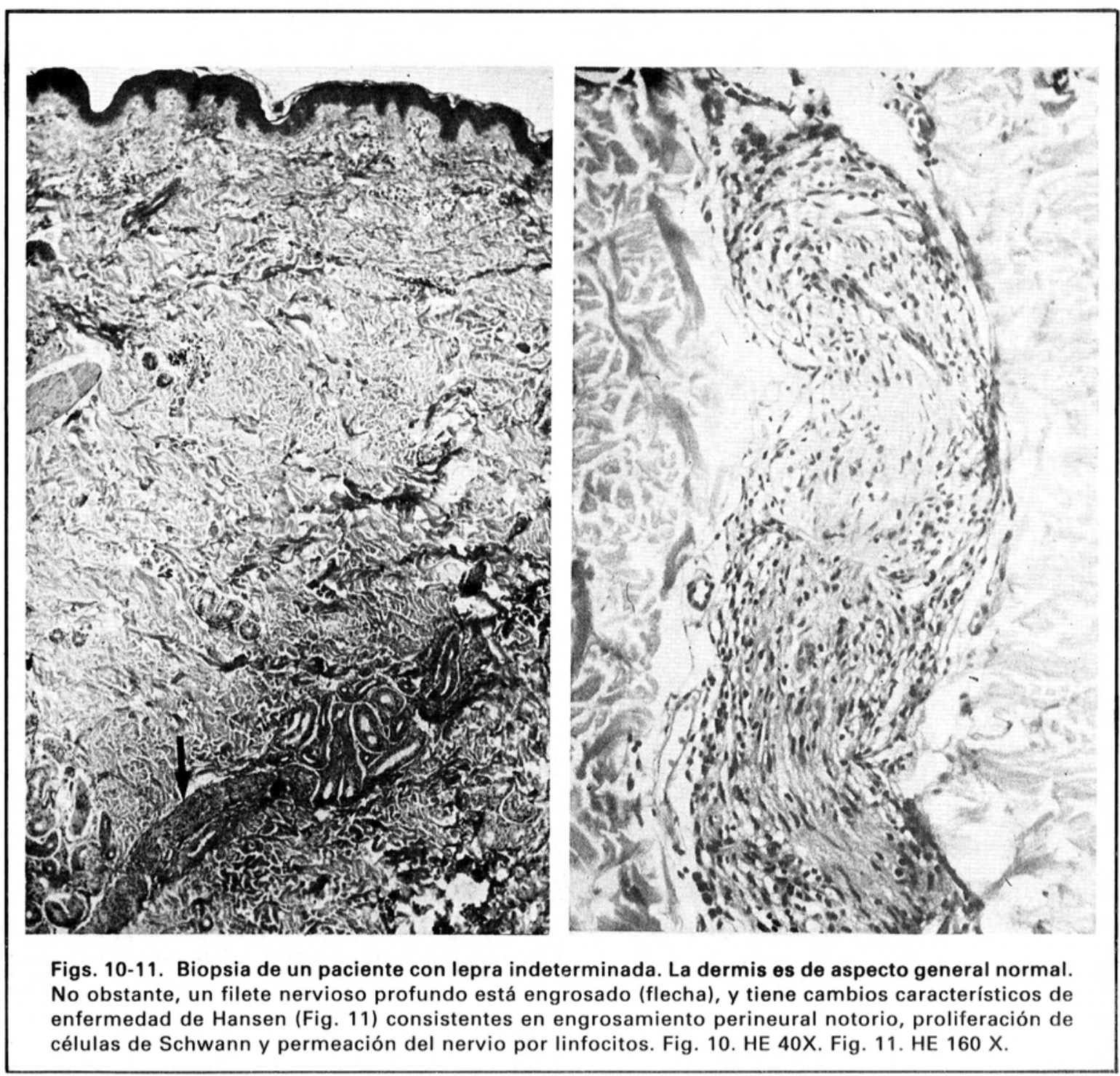




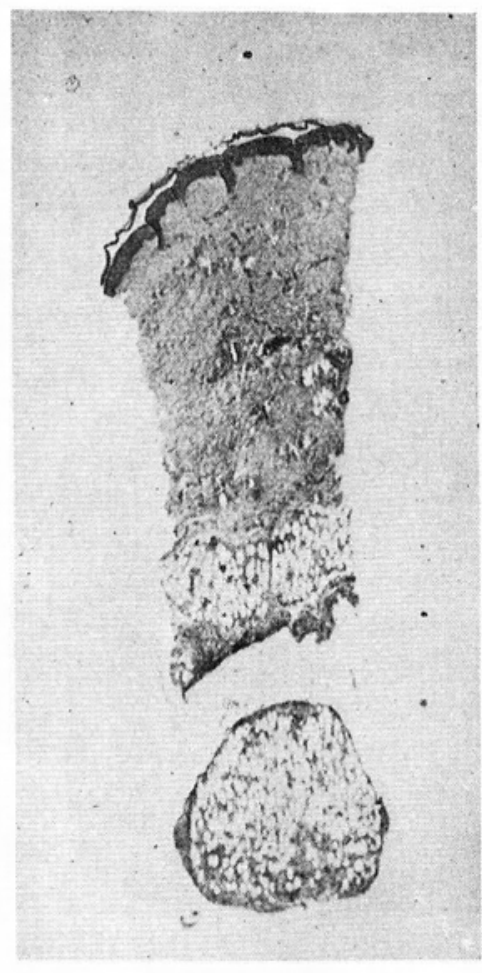

Fig. 12. "Punch" de una hipodermitis. Material no representativo porque no incluye suficientes lóbulos adiposos. HE $40 \mathrm{X}$.

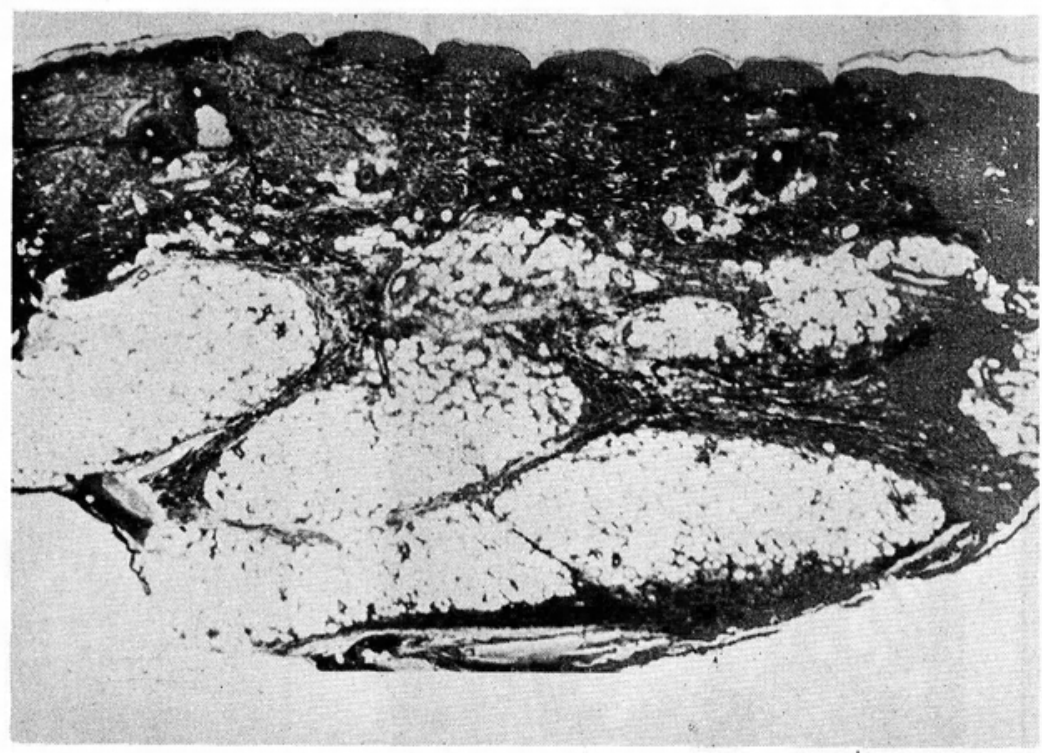

Fig. 13. Excelente biopsia para estudio de hipodermitis. Varios lobulillos y tabiques adiposos están presentes. Foto panorámica con lupa.

10. En las micosis subcutáneas y sistémicas que originen importante hiperplasia epitelial y costra, la biopsia superficial es inútil, pues no incluye suficiente dermis o hipodermis donde se observan los cambios diagnósticos (Figs. 14-15).

11. Las biopsias de tumores deben ser preferiblemente escisionales con un margen de seguirdad de 0,5 a $2 \mathrm{~cm}$. Cuando sea necesario practicar una biopsia de un queratoacantoma, se deben incluir los bordes laterales y toda la profundidad del tumor. (Figs. 1617), pues la arquitectura general de la neoplasia es la que permite diferenciarlo del carcinoma escamocelu$\operatorname{lar}^{(14,16)}$. Si el queratoacantoma es muy grande, se puede tomar la biopsia desde el centro del tumor, al borde del mismo, incluyendo toda la profundidad de la lesión ${ }^{(14,16)}$.

La biopsia superficial de un mioblastoma de células granulares puede diagnosticarse erróneamente como carcinoma escamocelular si no se incluye la parte profunda, rica en células granulares, típicas y diagnósticas de la lesión (Figs. 18-19).

En los linfomas cutáneos distintos de la micosis fungoide, los infiltrados tumorales diagnósticos tienden a localizarse en la dermis profunda y el límite dermohipodérmico; en la dermis papilar se ve componente inflamatorio. La biopsia pequeña y superficial de estas lesiones es inútil y puede originar diagnósticos no concluyentes o erróneos.

12. Las lesiones escoriadas, antiguas, cicatriciales o en involución no son útiles para el diagnóstico histopatológico; lo mismo sucede con las traumatizadas, infectadas o modificadas por el tratamiento. El uso de corticoides suprime la inflamación y si es prolongado, origina telangiectasias y atrofia. Si es posible, todo tratamiento local debe suprimirse siquiera dos semanas antes de practicar la biopsia cutánea. 


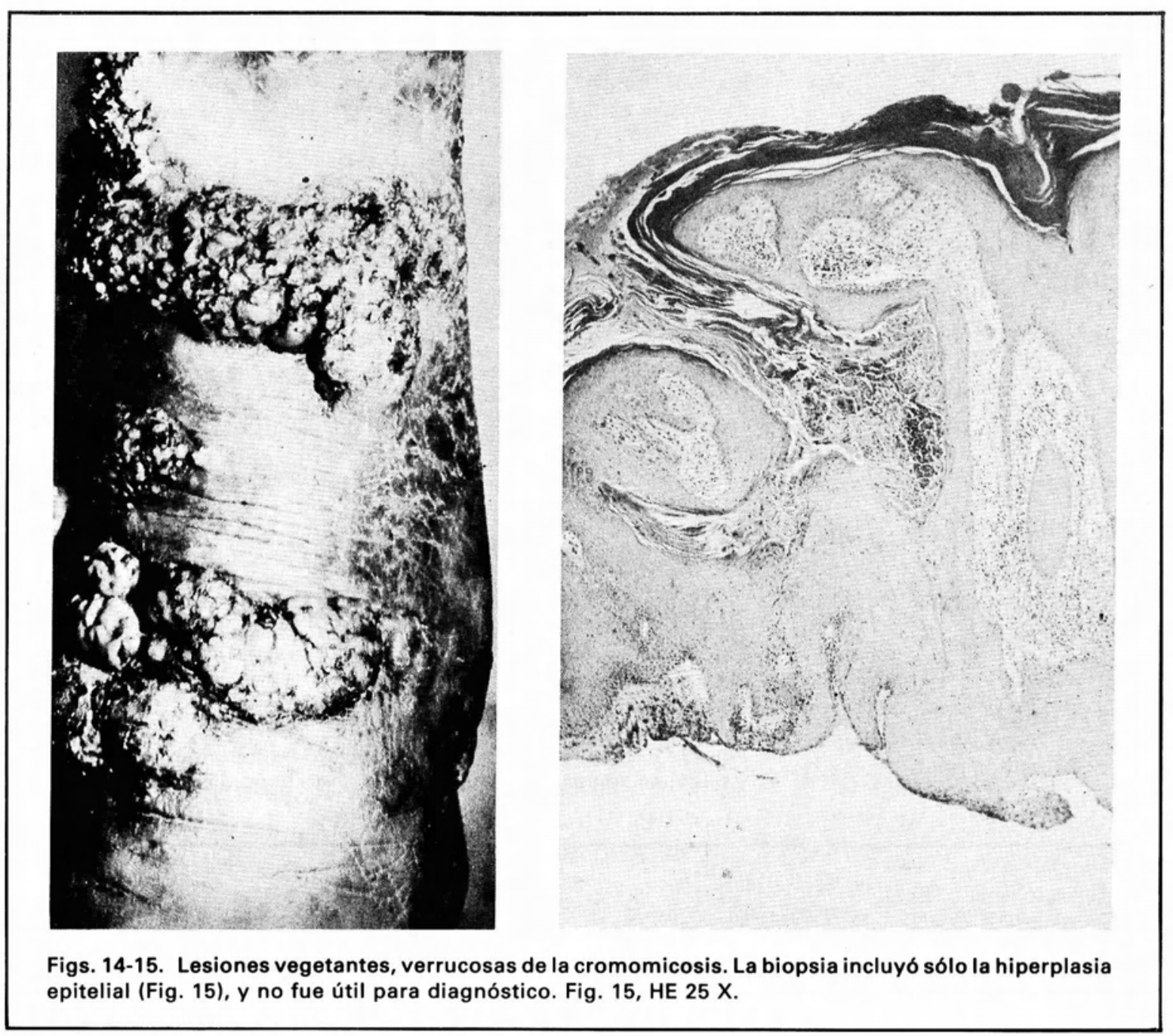

13. La obtención de una biopsia mediante electrocauterio o corriente eléctrica de alta frecuencia produce importantes alteraciones en el espécimen haciéndolo ilegible; por consiguiente este método no debe usarse.

14. Las biopsias tomadas para aislar virus, bacterias y hongos, deberán colocarse en un recipiente con solución salina estéril, en cantidad suficiente para apenas cubrir el espécimen y ser llevadas inmediatamente al laboratorio.

15. La biopsia para inmunofluorescencia se requiere en las enfermedades ampollosas de la piel y en las de naturaleza autoinmune o con complejos antígeno-anticuerpo $^{(18,18 \mathrm{~A})}$. Se recomienda tomar el espécimen de los $5 \mathrm{~mm}$ periféricos a la ampolla ${ }^{(18 \mathrm{~A})}$ y enviarse en fresco e inmediatamente para estudio. En las vasculitis, la piel sana interlesional, es el área recomendada.

Las técnicas de PAP y Avidina-Biotina pueden realizarse en tejido congelado y en material incluido en parafina ${ }^{(19)}$.

16. Las biopsias para microscopía electrónica se usan para investigación y para diagnóstico. Requieren selección rigurosa para que sean representativas, puesto que cada bloque final incluido debe tener apenas $1 \mathrm{~mm}$. El tejido extraido se debe colocar inmediatamente en el fijador adecuado, el más usado de los 
Fig. 16.

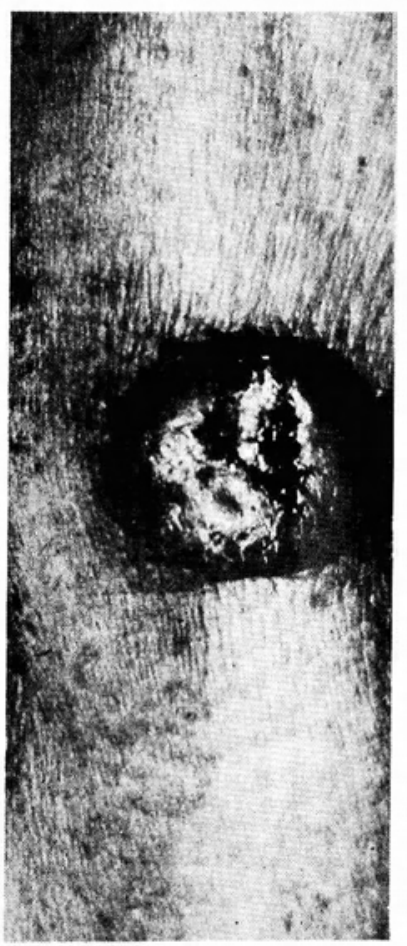

cuales es el glutaraldehído al 3\% en solución amortiguadora de fosfatos $0.1 \mathrm{M}$. Areas representativas de la lesión deben fijarse en tamaños lo más pequeños posibles, de unos $3 \mathrm{~mm}$, que incluyan epidermis y dermis. Luego de 30-60 minutos de fijación se puede cortar la biopsia a tamaño de 0.5 a $1 \mathrm{~mm}$, continuándose la fijación hasta un total de 2-12 horas. La fijación prolongada en glutaraldehído no daña el espécimen pero no se recomienda porque disminuye la calidad de la imagen ultraestructural. En el laboratorio, la biopsia se lava en buffer, se postfija durante 2 horas en $\mathrm{OsO}_{4}$ al $1 \%$ en solución tampón de fosfato $0.1 \mathrm{M}$, se deshidrata y se incluye en resinas epóxicas, vigilando la orientación adecuada con un estereomicroscopio.

\section{BIOPSIA POR SACABOCADO:}

Es la técnica más usada porque requiere poco tiempo y mínimo entrenamiento. Además, produce una herida pequeña, uniforme, de bordes lisos y con mínima incidencia de complicaciones: infección, hemorragia, cicatrización retardada o desfiguración. Se debe practicar una técnica estéril en pacientes con riesgo de infeciones como los inmunosuprimidos o aquellos con prótesis valvulares cardíacas ${ }^{(5)}$.

Fig. 17.

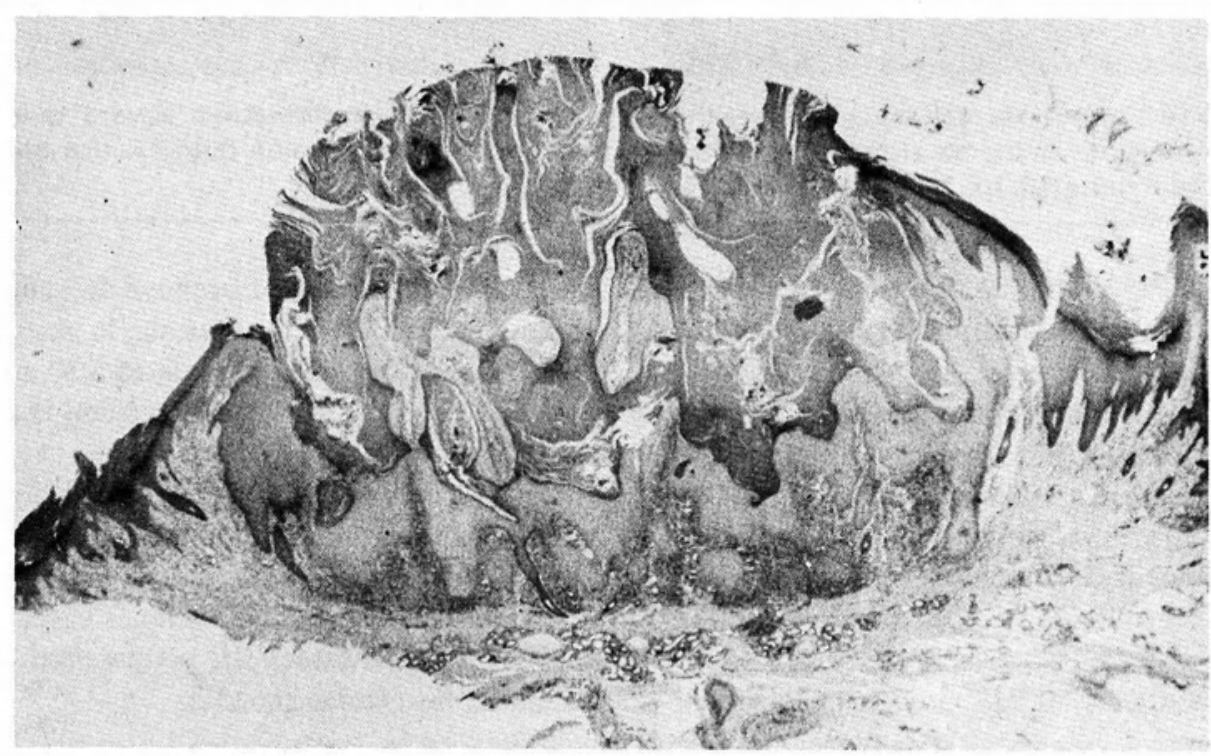

Figs. 16-17. La biopsia del queratoacantoma debe incluír ambos bordes de la lesión y toda la profundidad de la misma, pues es su arquitectura general la que permite su diferenciación del carcinoma escamocelular. Fig. 17, HE 25 X. 


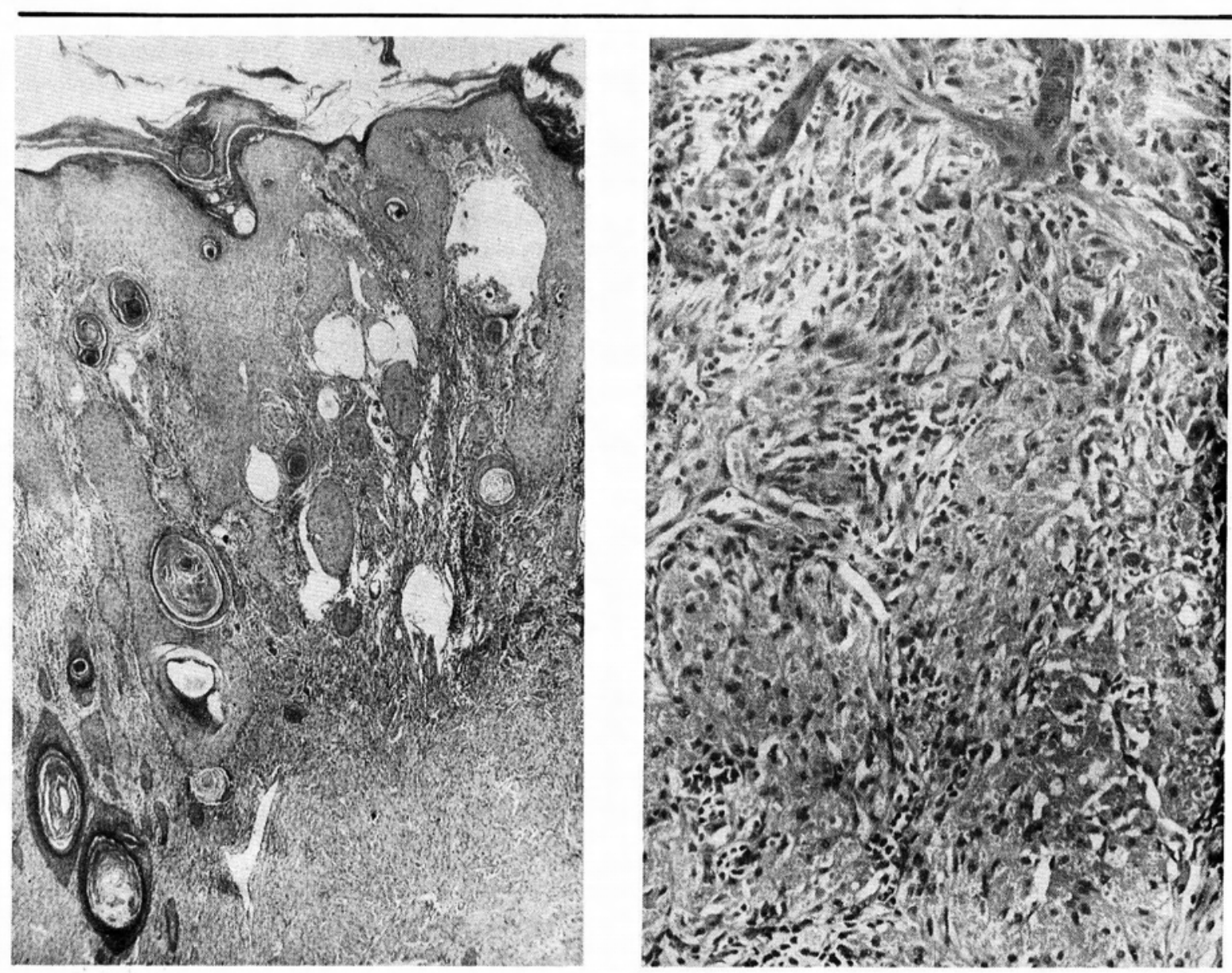

Figs. 18-19. Tumor de células granulares. Hiperplasia pseudoepiteliomatosa severa que puede confundirse con carcinoma si no se incluye el área diagnóstica de la lesión (Fig. 19) rica en células granulares. Figura 18. HE 25 X. Fig. 19, HE 400 X.

Se debe marcar el sitio de donde se va a tomar la biopsia, antes de hacer la infiltración del anestésico, para evitar que "desaparezca" la lesión escogida, especialmente cuando se trate de una mácula hipocrómica o de un nódulo. Si se practica desinfección del área, se debe tener mucho cuidado para dejar intactas las escamas, costras o vesículas que allí hubiere. Por esta razón, algunos dermatólogos prefieren realizar la biopsia sin hacer ningún tipo de asepsia local.

El anestésico local de elección es la lidocaína al $1 \%-2 \%$, que muy rara vez origina reacciones alérgicas. La infiltración se realiza puncionando la periferia de la lesión llevando la punta de la aguja hasta la dermis profunda; la cantidad requerida es de 0.2 a 1 $\mathrm{ml}$. El uso del anestésico con epinefrina facilita el procedimiento porque disminuye el sangrado y aumenta la duración de la anestesia; la vasoconstricción máxima nunca se logra antes de 15 a 20 minutos. Esta mezcla se contraindica en sitios como la punta de los dedos o de la nariz, glande, lóbulo de la oreja, en pacientes con enfermedad cardiovascular importante, en los que esten tomando bloqueadores beta, y cuando la vasoconstricción pueda interferir con los hallazgos histopatológicos, como las lesiones vasculares primarias $^{(20)} \mathrm{o}$ en las mastocitosis porque produce degranulación de las células cebadas.

La infiltración del anestésico puede causar artificios que deberán ser reconocidos por el patólogo, como los originados con el Madajet o dermojet, un instrumento sin aguja, de inyección por presión ${ }^{(21-24)}$. 
La lidocaína tiene propiedades antibacterianas especialmente cuando se mezcla con metilparabeno, como la disponible entre nosotros. Por esta razón, los cultivos bacteriológicos de un espécimen obtenido por biopsia deben hacerse en las dos horas posteriores a su toma ${ }^{(15)}$.

Los sacabocados son instrumentos cilíndricos, cortantes, con diámetros que van de 2 a $10 \mathrm{~mm}$ (Fig. 20); los de menos de $4 \mathrm{~mm}$ sólo tienen aplicación en un limitado número de situaciones como la confirmación histológica de un carcinoma basocelular previa a la cirugía y en algunas biopsias de la cara y del glande. El "punch" de piel de $2 \mathrm{~mm}$ nunca es un espécimen satisfactorio y requiere cortes seriados para demostrar la lesión básica. Su facilidad de manejo ha hecho que tenga un uso general no indicado. El $42 \%$ de las 469 biopsias revisadas, se tomó con sacabocados menor de $3 \mathrm{~mm}$. El "punch" de $2 \mathrm{~mm}$ introducido hasta la dermis media únicamente, constituye el principal factor de dificultad en la interpretación de las biopsias de piel.

Para tomar la biopsia, el sacabocado se presiona y se rota introduciéndolo hasta el tope $(5-7 \mathrm{~mm}$ de profundidad) (Fig. 21). La dermis tiene su mayor grosor en el tronco y el muslo, donde alcanza $4 \mathrm{~mm}$ de espesor $^{(16)}$. Siempre se debe llegar hasta la hipodermis para que la biopsia sea más representativa y la cicatrización más rápida y fácil porque la rica vascularización proveniente de la hipodermis facilita la reparación tisular. El diagnóstico de muchas dermatosis se basa en la distribución de los infiltrados alrededor del plejo vascular profundo ${ }^{(16,24)}$, estructura que podrá ser analizada tan sólo si la biopsia incluye hipodermis. Se deberá prestar atención a estructuras subyacentes como nervios y vasos, especialmente en regiones como las márgenes digitales, la cara ventral de la muñeca y el dorso del pie.

Las biopsias del cuero cabelludo deben hacerse inclinando el sacabocados unos $20^{\circ}$ de tal manera que se ajuste al eje de los folículos pilosos. También se deberá profundizar lo suficiente en la hipodermis para incluir papilas pilosas.

La biopsia tomada se tracciona suavemente con un gancho de piel. El cilindro se corta en lo profundo con bisturí o con tijeras (Fig. 21). La compresión con pinzas o la punción con agujas origina artificios que pueden echar a perder el espécimen o confundir el diagnóstico (Figs. 22-24). Las pinzas no deben tocar el espécimen ${ }^{(14)}$. La hemostasia se consigue con simple presión o con cáusticos como el ácido tricloroacético o el percloruro férrico. Este último puede dejar a veces una pigmentación marrón clara, permanente en la cicatriz $^{(5)}$. La solución de Monsel (subsulfato férrico) usada como hemostático, puede originar una lesión inflamatoria atípica, muy celular con frecuentes mitosis y cristales irregulares que puede confundirse con tumores malignos. Esta solución no se utiliza en nuestro medio.

La electrocoagulación no se recomienda porque produce una quemadura que aumenta la cicatriz. En pacientes con marcapasos puede interferir o bloquear la acción eléctrica de éstos.

Se deberán suturar los sacabocados de $6 \mathrm{~mm}$ o más y preferiblemente aquellos tomados de la cara, usando seda o nylon de calibres 4 ceros, 5 ceros o 6 ceros. También se pueden usar tiras adhesivas (Micropore ${ }^{(\mathrm{R})}$ ) colocadas sobre el defecto, durante 14 a 21 días; a pesar de que la sutura mejora los resultados cosméticos, puede incrementar el tiempo de cicatrización y el riesgo de infección; no deberán suturarse los sitios de biopsias en dermatosis infecciosas a no ser que la hemostasia así lo requiera ${ }^{(5)}$.

En resumen la biopsia con sacabocados debe hacerse con los de diámetro mayor de $3 \mathrm{~mm}$ y debe tener una profundidad mayor de $5 \mathrm{~mm}$, para que siempre incluya hipodermis.

\section{BIOPSIA POR AFEITADO (REBANADO):}

La biopsia por rebanado es útil tan sólo cuando la patología está limitada a la epidermis y dermis papilar. Permite la remoción de los crecimientos epiteliales benignos exofíticos como queratosis seborreicas, nevus y verrugas virales; es útil para confirmar el diagnóstico de carcinoma basocelular antes del tratamiento definitivo pero no sirve para valorar los márgenes tumorales. El procedimiento es rápido y sencillo de realizar, cura rápidamente y los resultados cosméticos son muy buenos. Tiene la gran ventaja de dejar intactos los niveles inferiores de la dermis para eventuales procedimientos posteriores, como resección, curetaje, electrocirugía o criocirugía ${ }^{(17)}$. 

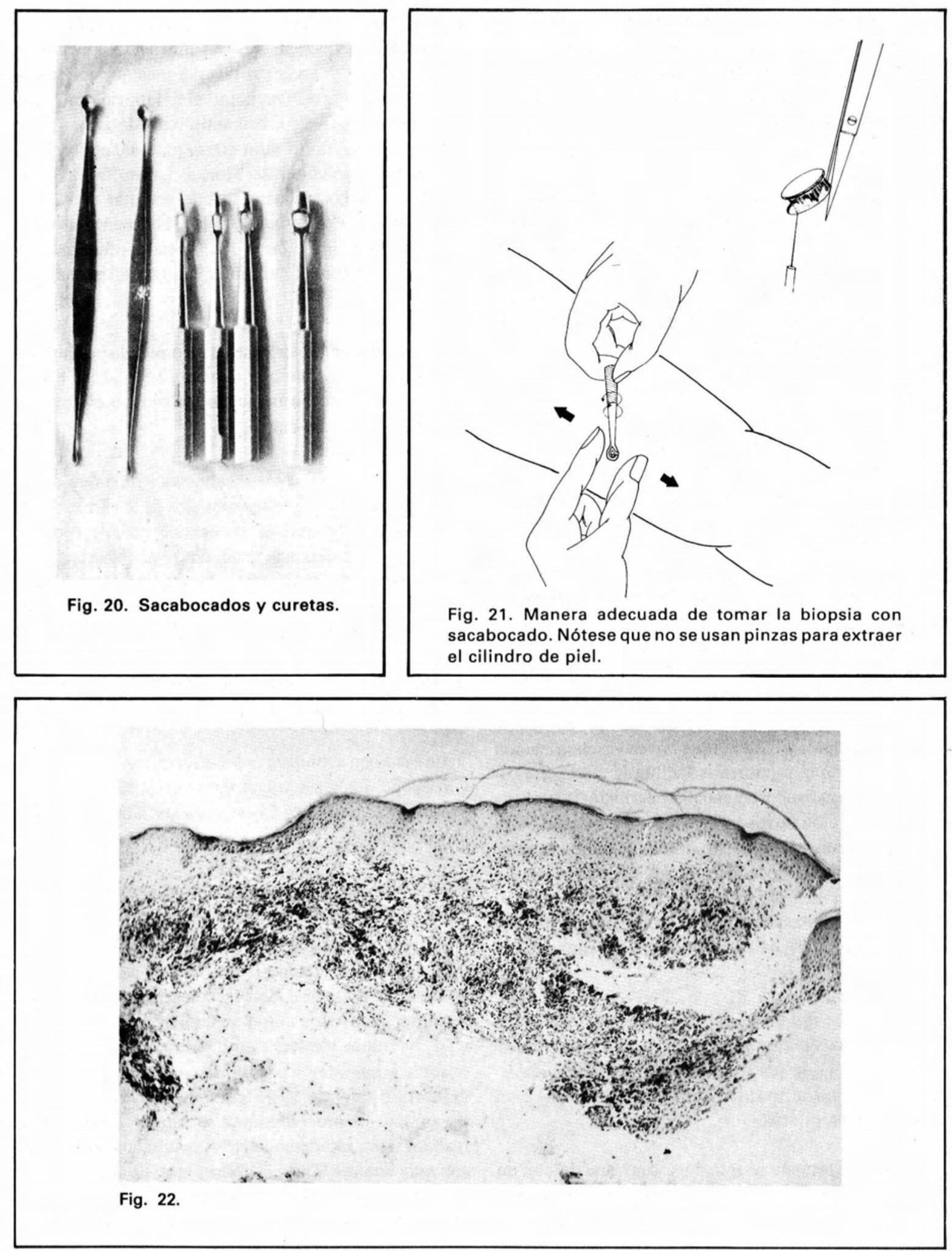


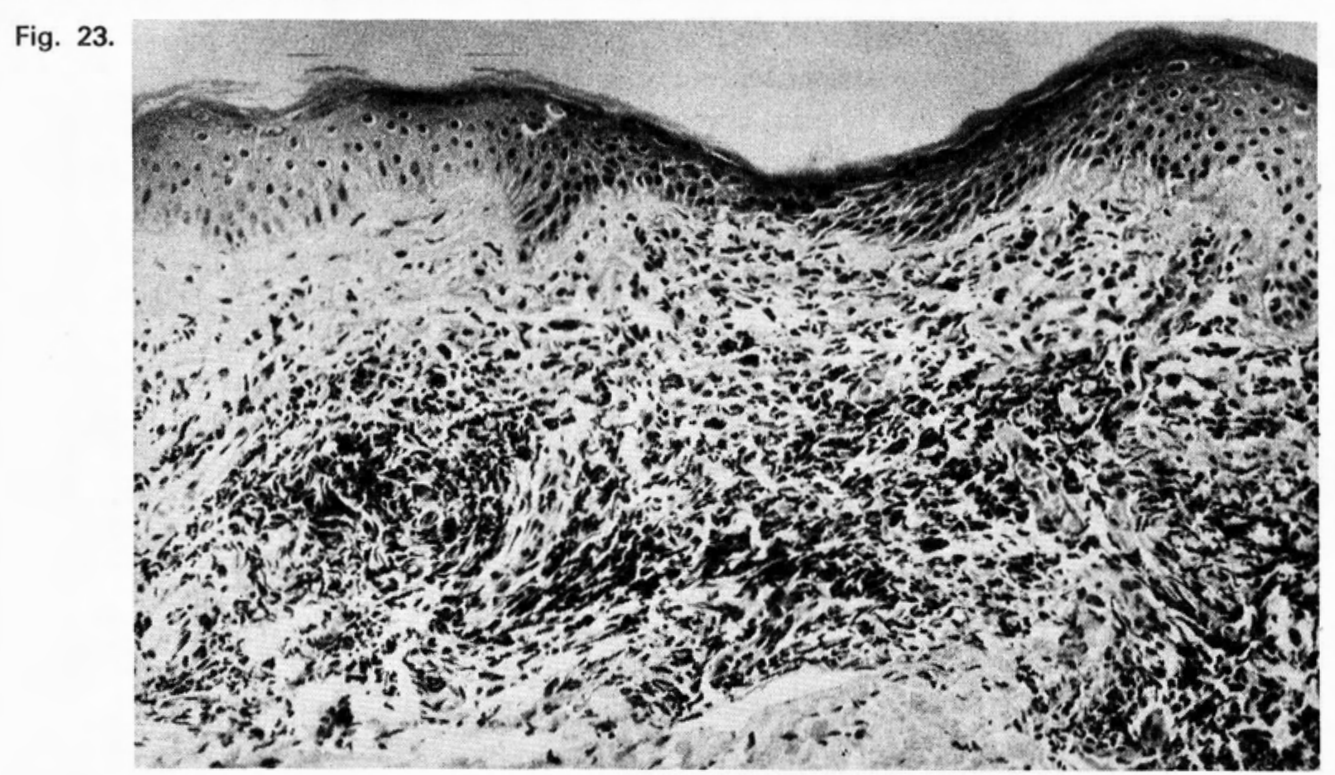

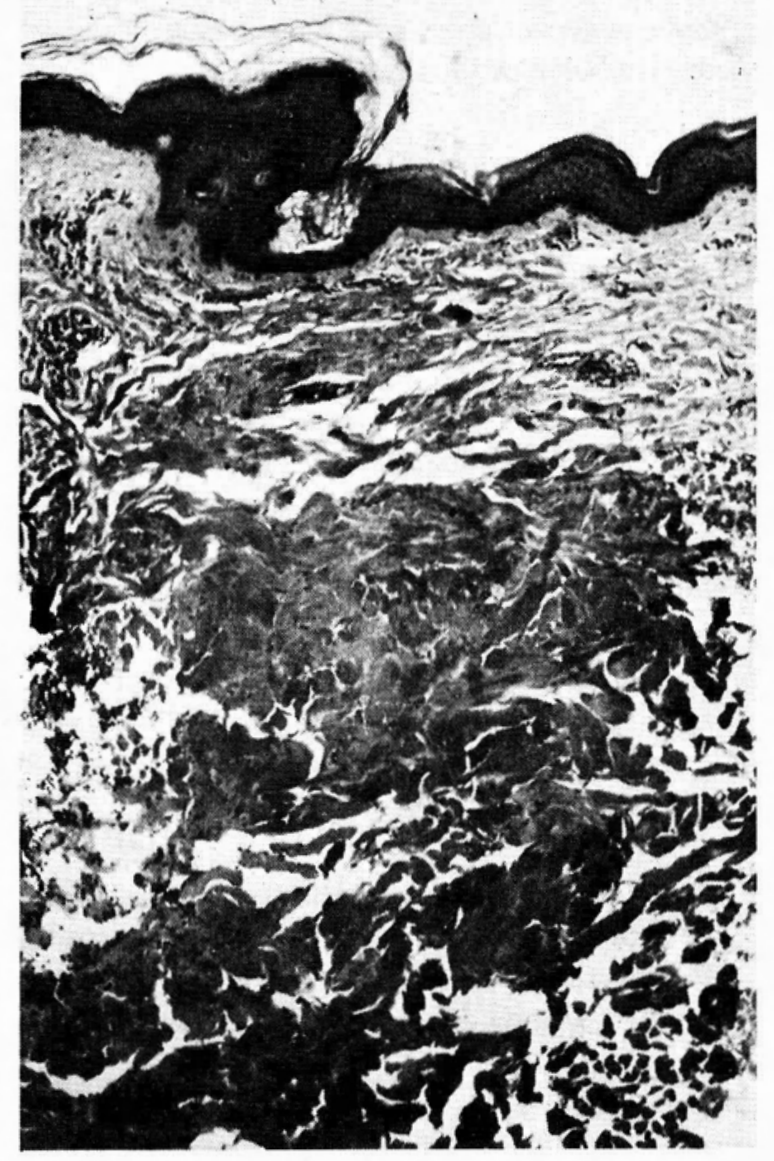

Fig. 24.

Figs. 22-24. Huellas traumáticas de la aguja (Fig. 22) y de compresión por pinza (Fig. 23), que hacen irreconocibles los infiltrados dérmicos (Figs. 22-23). La compresión en la figura 24 produce cambios dérmicos que semejan escleroderemia. Fig. 22, HE 63 X. Figs. 23-24, HE $160 \mathrm{X}$.

Requiere la limpieza y la anestesia del área, indicadas para la biopsia con sacabocados. El afeitado realizado inmediatamente después de la infiltración anestésica, aprovechando que el tejido se encuentra elevado, facilita una resección más amplia. Se puede usar una cuchilla de bisturí o la mitad de una hoja de afeitar.

Los rebanados de nevus celulares intradérmicos pueden originar una reacción reparativa de las células nevicas remanentes que llega a confundirse con un melanoma si no se conoce el antecedente o si no se dispone de los cortes de la lesión inicial para su revisión microscópica ${ }^{(26)}$.

\section{BIOPSIA POR CURETAJE:}

Es útil para remover verrugas, moluscos, queratosis y carcinomas basocelulares. La cureta es un instrumento circular cortante (Fig. 20), disponible en varios diámetros; el más utilizado es el de $4 \mathrm{~mm}$. El tejido resultante para la histopatología es difícil de evaluar por lo distorsionado, fragmentado y escaso. En caso 
de sospecharse un carcinbma basocetular; practicar una biopsia por rebanado previa a la electrofulguración y curetaje. El paúlogencenocer este procedimiento para no informar estas biopsias como "carcinoma basocelular incompletamente resecado". El curetaje se ha considerado como la "antianatomía patológica”. Encierra el riesgo de fragmentar un carcinoma escamocelular o un melanoma.

\section{BIOPSIA INCISIONAL Y ESCISIONAL:}

Por definición, la biopsia incisional es aquella que extrae parte de la lesión; la escisional abarca la totalidad de la misma. La segunda es el método de elección para tumores de dignóstico incierto; para estudios múltiples de la misma lesión: cultivos, IF, etc.; para remover lesiones mayores de $6 \mathrm{~mm}$, y a veces para lograr resultados cosméticos más favorables. Es la técnica de elección cuando se sospecha un melanoma pues permite evaluar la profundidad de invasión del tumor y puede evitar intervenciones secundarias.

\section{BIOPSIA UNGUEAL:}

Es traumática, dolorosa, difícil de realizar y de interpretar. Puede acarrear consecuencias cosméticas permanentes por lo cual debe realizarla un médico con experiencia. Demanda una técnica estéril estricta. La anestesia debe hacerse con lidocaína sin vasoconstrictor. Măs de $5 \mathrm{ml}$ de anestésico pueden interferir peligrosamente el flujo sanguíneo(27). El sangrado puede controlarse con un dren de Penrose como torniquete, que nunca se aplicará por más de 15 minutos $^{(27)}$. Sólo la presión o el Oxisel ${ }^{(\mathrm{R})}$ pueden usarse como hemostáticos ${ }^{(28)}$. El bloqueo neural digital se logra infiltrando un anillo alrededor del área dorsolateral, desde el hueso hasta la piel ${ }^{(27)}$. La anestesia regional con bloqueo metacarpiano, axilar o del plejo braquial, así como la anestesia general pueden ser necesarias eventualmente ${ }^{(27)}$.

La biopsia ungueal en nuestra experiencia sirve para diagnosticar onicomicosis, psoriasis, liquen plano, verrugas, granulomas telangiectásicos, carcinoma escamocelular y melanomas.

Las onicomicosis se diagnostican en la placa ungueal evulsionada o en biopsias tomadas con tijera que incluyan placa ungueal distal e hiponiquio. Las hifas, esporos y micelios no son aparentes en la H.E., por lo que es mandatoria y prioritaria la coloración de PAS (Figs. 25-27).

Para facilitar el corte, la placa ungueal se ablanda con fenol al $5 \%$ o con $\mathrm{KOH}$ al $10 \%$, durante 2-3 horas.

La biopsia del lecho ungueal se puede tomar con sacabocados de $3 \mathrm{~mm}$ si se adelgaza antes la placa ungueal $^{(27)}$. También se puede evulsionar parcialmente la placa de la uña y tomar luego la biopsia del lecho con una incisión elíptica, seguida de sutura con dexón $4 \operatorname{ceros}^{(27)}$ (Fig. 28).

La biopsia de la matriz ungueal es obligatoria sólo cuando se sospecha un tumor maligno, usualmente melanoma. Si el diagnóstico clínico es de psoriasis o liquen plano, se prefiere tratar al paciente como tal, sin correr los riesgos cosméticos permanentes que originaría la biopsia ${ }^{(28)}$. Stone, et $a^{(28)}$ enumeran catorce criterios generales útiles en la biopsia ungueal, de los cuales extractamos los siguientes:

1. Se debe tratar la infección secundaria antes de hacer biopsia periungueal.

2. Es conveniente hacer una radiografía antes de la biopsia si la lesión ungueal es "distorsionada" o muy irregular.

3. Las biopsias periungueales son fáciles de hacer, lo mismo que las del pliegue ungueal posterior. En este caso es conveniente no incluir el borde del pliegue ungueal.

4. La biopsia de la matriz ungueal se debe hacer sólo si se sospecha un tumor maligno. Si la lesión se extiende al lecho ungueal, debe hacerse primero la biopsia de esta zona.

5. Cuando se haga biopsia de la matriz o del lecho, se debe adelgazar la placa ungueal por raspado. Es conveniente dejar la placa en su sitio para que sirva como guía del proceso de reparación.

6. En las uñas de los artejos las biopsias pueden ser más amplias porque el aspecto cosmético es menos importante. 


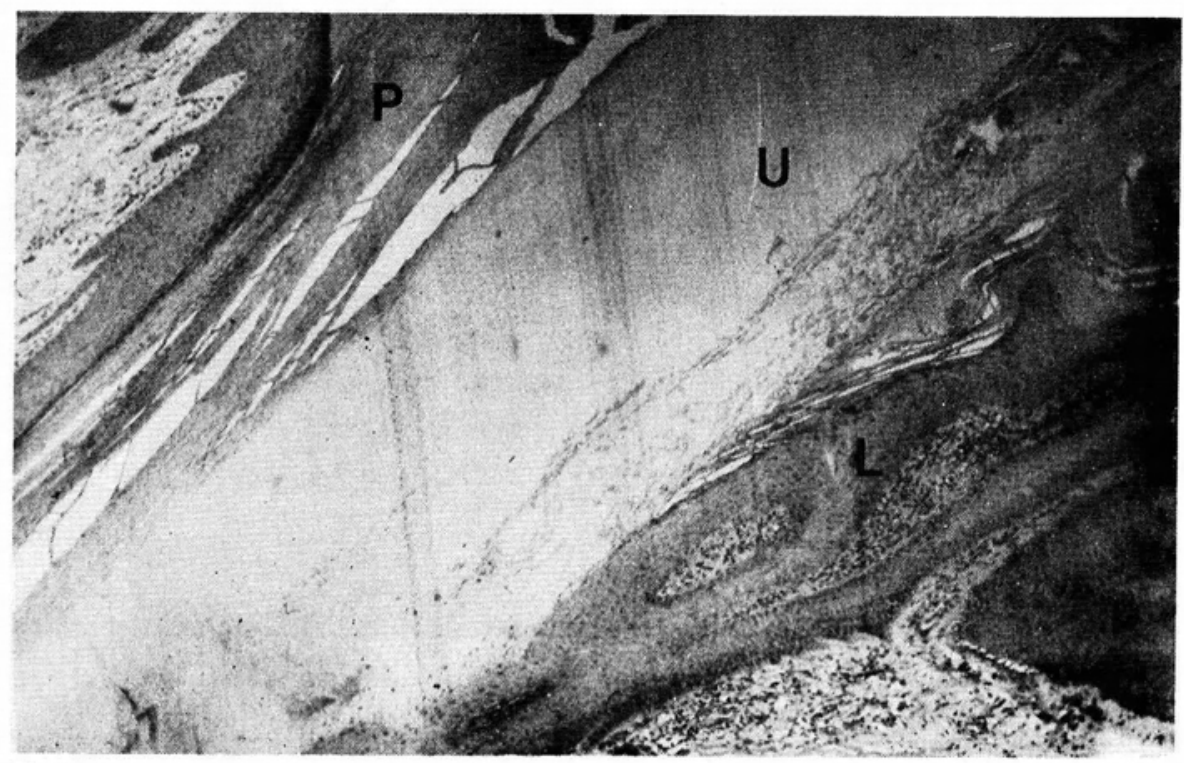

Fig. 25.

Figs. 25-26. Cortes seriados de la misma biopsia ungueal teñidos con HE y PAS. P: pliegue ungueal proximal. U: placa ungueal. L: lecho ungueal. Las hifas y micelios sólo se ven en la coloración de PAS. (Flecha, fig. 26). Fig. 25, HE 63X. Fig. 26, PAS 63 X.

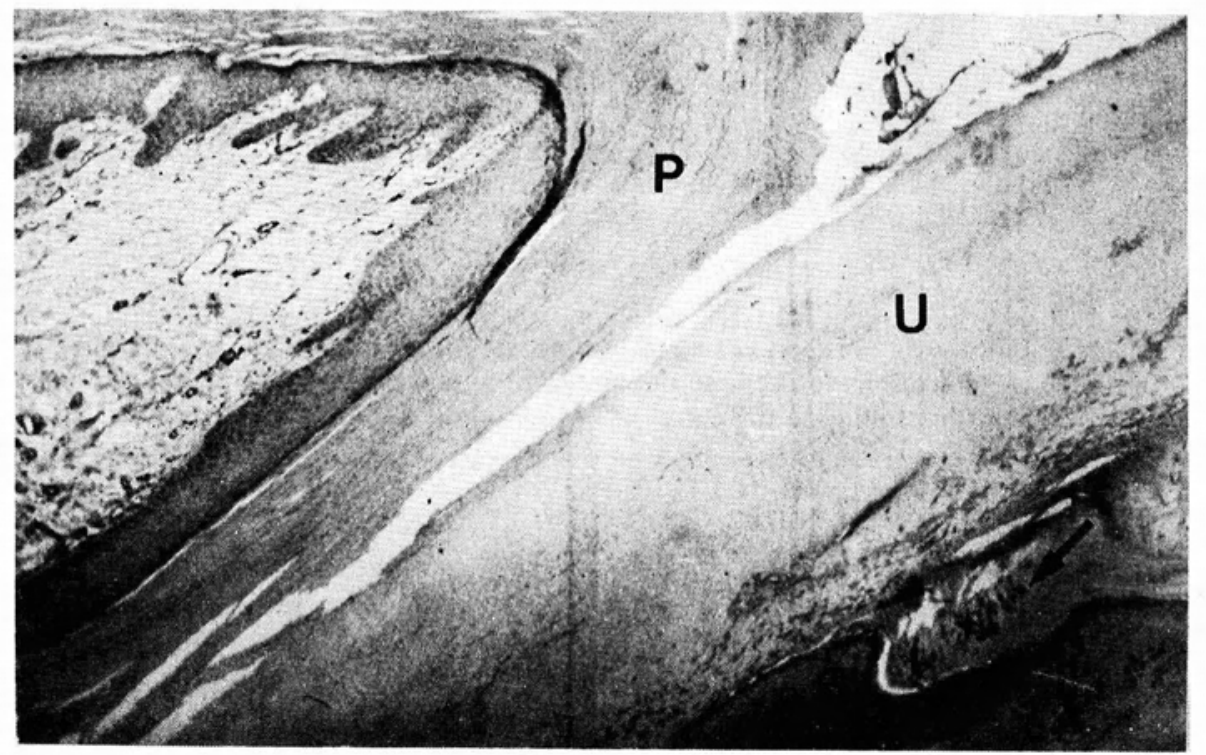

Fig. 26. 

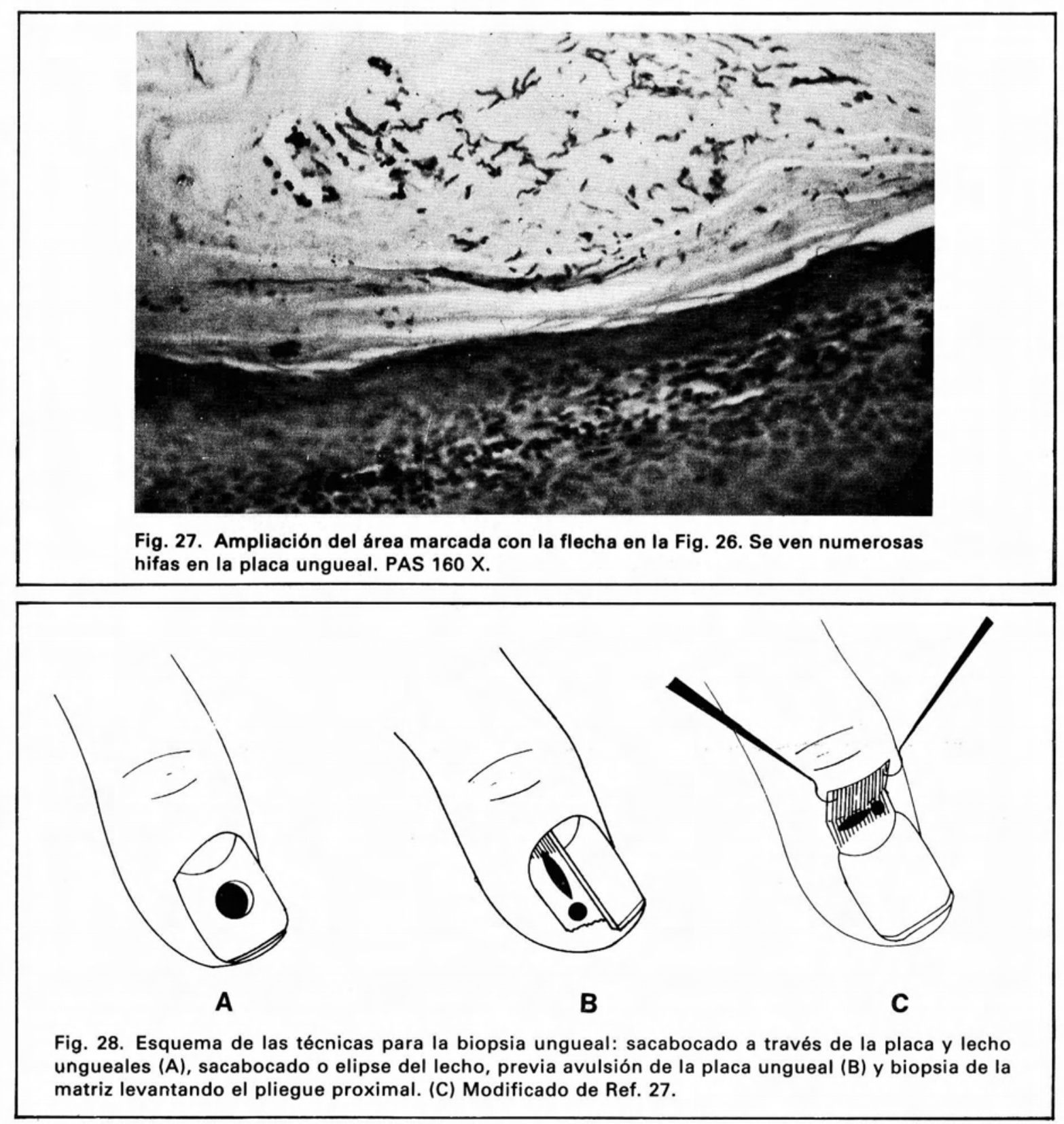

\section{PROCESO DE LA BIOPSIA:}

La biopsia se coloca sobre un papel cualquiera, para impedir que se contraiga o pliegue ${ }^{(28)}$ y se sumerge enseguida en el fijador que preferiblemente debe ser formol tamponado al $10 \%$. La cantidad de fijador deberá ser 20 veces el volumen del espécimen. El tiempo de fijación no debe ser inferior a 18 horas. Si la anchura del espécimen es mayor de $4 \mathrm{~mm}$, puede cortarse, de la hipodermis hacia la epidermis, una vez que el tejido se haya endurecido por el fijador, lo cual sucede luego de las seis primeras horas de fijación. Este es un paso muy útil que facilita la orientación adecuada del espécimen por el técnico. Si la biopsia se corta en fresco, se pueden producir desgarros y artificios (Figs. 22-24). La fijación y congelación simultáneas producen cristalización y vacuolización del tejido, volviéndolo inútil para su estudio (Fig. 29). 


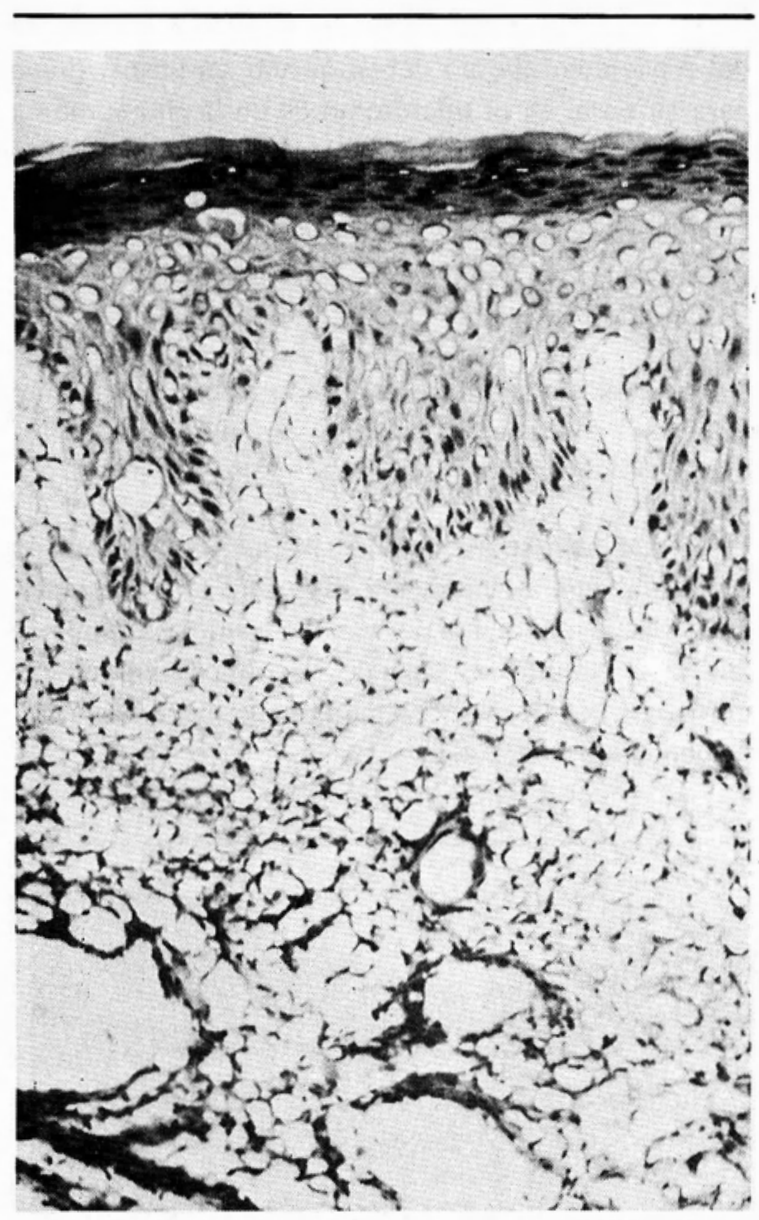

Fig. 29. Vacuolización extrema debida a congelación de la biopsia durante el proceso de fijación. La imagen es inútil para estudio. HE $160 \mathrm{X}$.

El patólogo al interpretar los hallazgos microscópicos, está contestando una interconsulta. El espécimen enviado debe estar acompañado siempre de una hoja de remisión que incluya la información pertinente: edad, sexo y raza del paciente, descripción de las lesiones, tiempo de evolución, sitio de toma de la biopsia y los posibles diagnósticos clínicos.

"Los médicos que creen que el patólogo debe llegar a una diagnóstico objetivamente, sin la influencia de opiniones o datos clínicos, deben saber que no puede ofrecer un servicio óptimo ni para el paciente ni para el clínico, si no conoce la historia completa. Comedidamente le recordamos al clínico que nos sentimos tan contentos confirmando su diagnóstico como improbándolo. Es deplorable la actitud de no pocos médicos que rehusan suministrar datos tan básicos como edad, sexo, o color de la piel del paciente"(24).

La descripción macroscópica debe ser minuciosa en casos de tumores y de biopsias incisionales o escisionales. La presencia de nódulos e irregularidades en la superficie de la biopsia y el tamaño de la misma deben consignarse en forma precisa. Los sacabocados, rebanados y mini-biopsias sólo deben indicar el tamaño de las mismas. Siempre se debe afirmar si hay o no hipodermis reconocible macroscópicamente porque se puede orientar erróneamente y no aparecer en los cortes microscópicos.

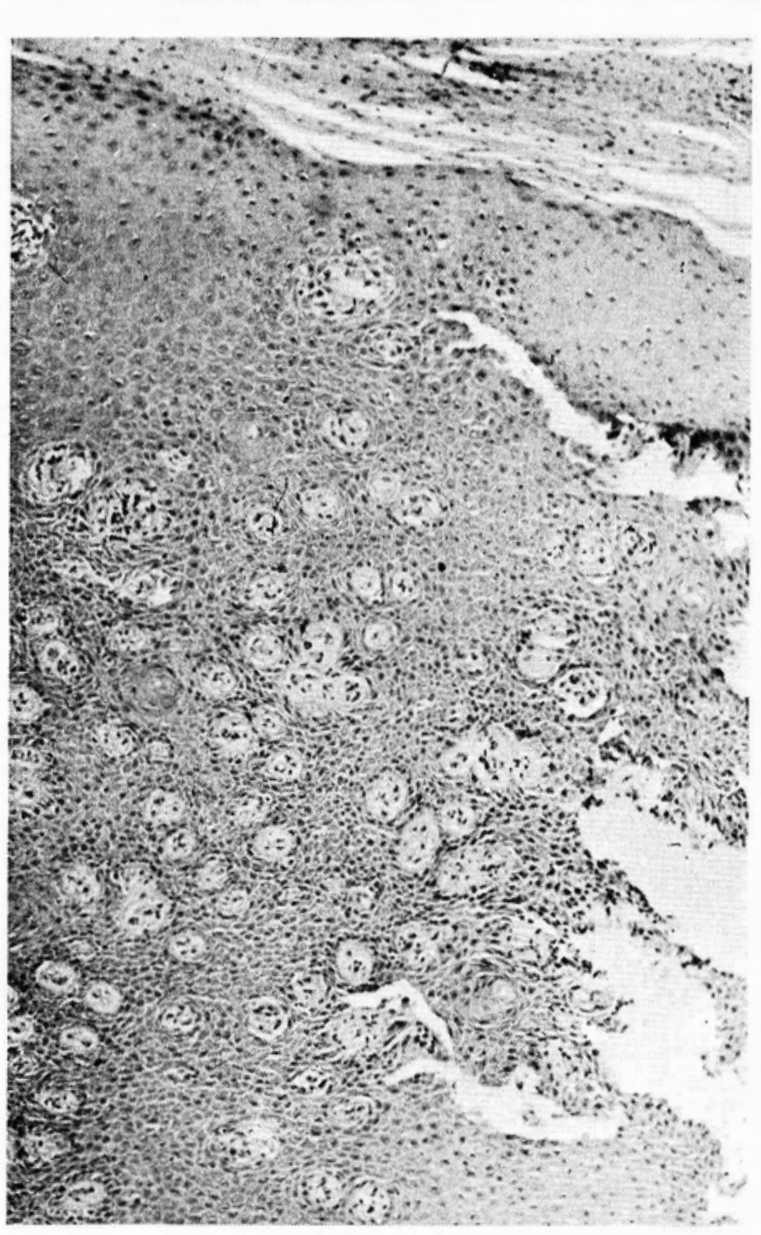

Fig. 30. Biopsia de la palma, impropiamente orientada, en corte transversal, inútil para estudio. HE $63 \mathrm{X}$. 
Los especímenes iguales o mayores de $4 \mathrm{~mm}$ obtenidos por sacabocados se deben cortar con una cuchilla de afeitar nueva, de tal manera que se incluyan las dos porciones, representando el primer plano de corte al centro del cilindro. Los sacabocados de $3 \mathrm{~mm}$ o menores se deberán incluir verticalmente, sin cortarse.

Los sacabocados de la piel volar y las biopsias por afeitado son difíciles de orientar porque tienden a ser aplanadas o lenticulares (Fig. 30). Deben biseccionarse y ponerse de canto para cortarlas con el micrótomo, siguiendo la superficie del corte macroscópico.

El estudio de las líneas de resección de los carcinomas basocelulares, escamocelulares y melanomas en una biopsia escisional es muy importante ${ }^{(30,31)}$. Los métodos son numerosos (Figs. 31-34). El mejor es aquel con el cual el patólogo esté más familiarizado ${ }^{(31)}$.
La importancia de marcar con tinta china los bordes del espécimen que no deben quedar en primer plano para su corte en el micrótomo es un hecho común a todos. Cuando se sospeche melanoma debe procederse según el método de Breslow (Fig. 33) que permite establecer exactamente el sitio de mayor grosor de la lesión y su nivel de invasión, esencial en el pronóstico y manejo del paciente ${ }^{(14,17,31)}$.

La neoplasia se informará como "incompletamente resecada" cuando esté presente en cualquiera de los márgenes quirúrgicos.

En nuestra experiencia los histiocitomas fibrosos de la piel incompletamente resecados, no presentan recidivas posiblemente porque son lesiones inflamatorias y no tumorales. Cuando un tumor histiocitario fibroso de la piel manifiesta recidivas, debe evaluarse su potencial malignidad.

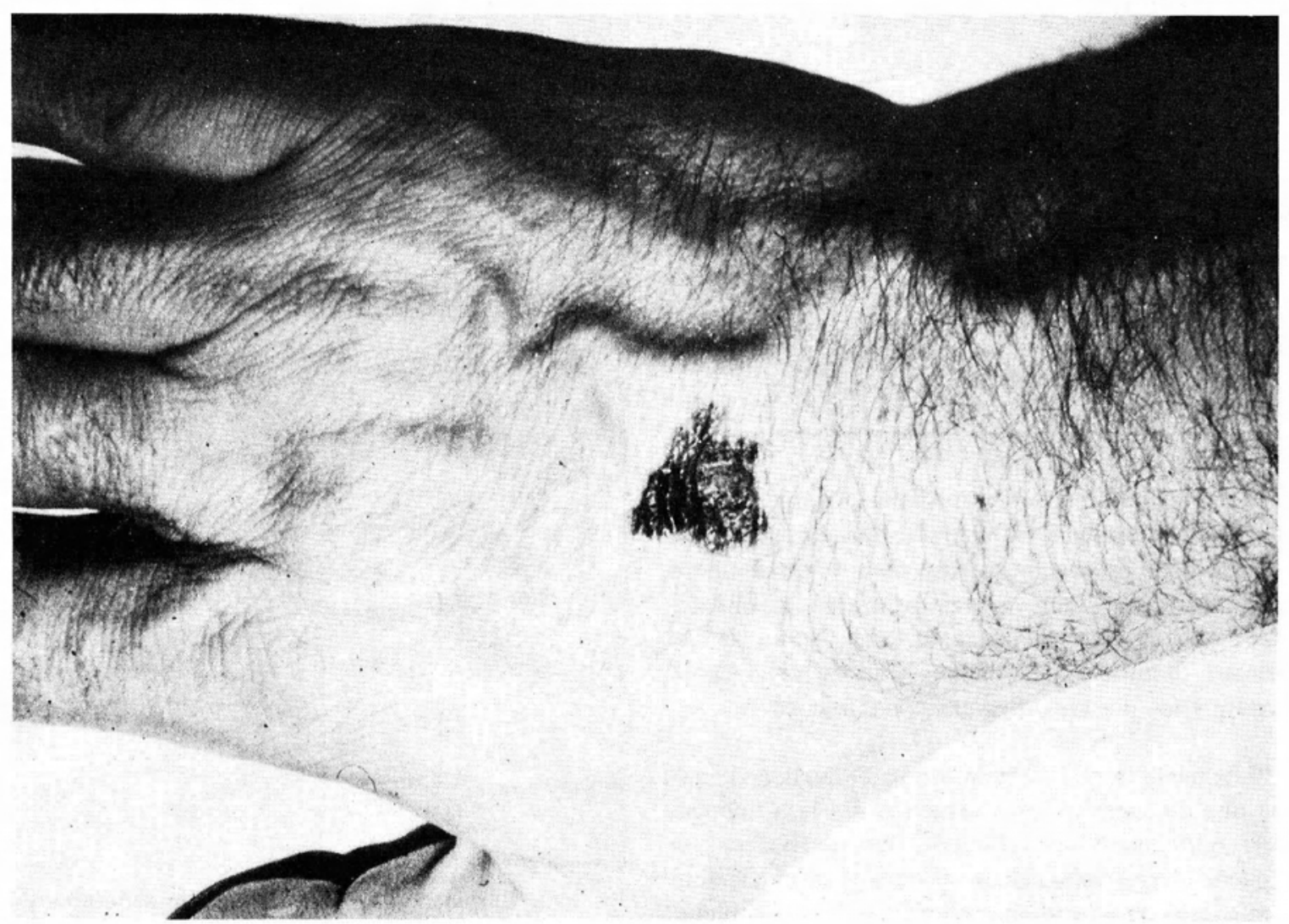

Fig. 31. 


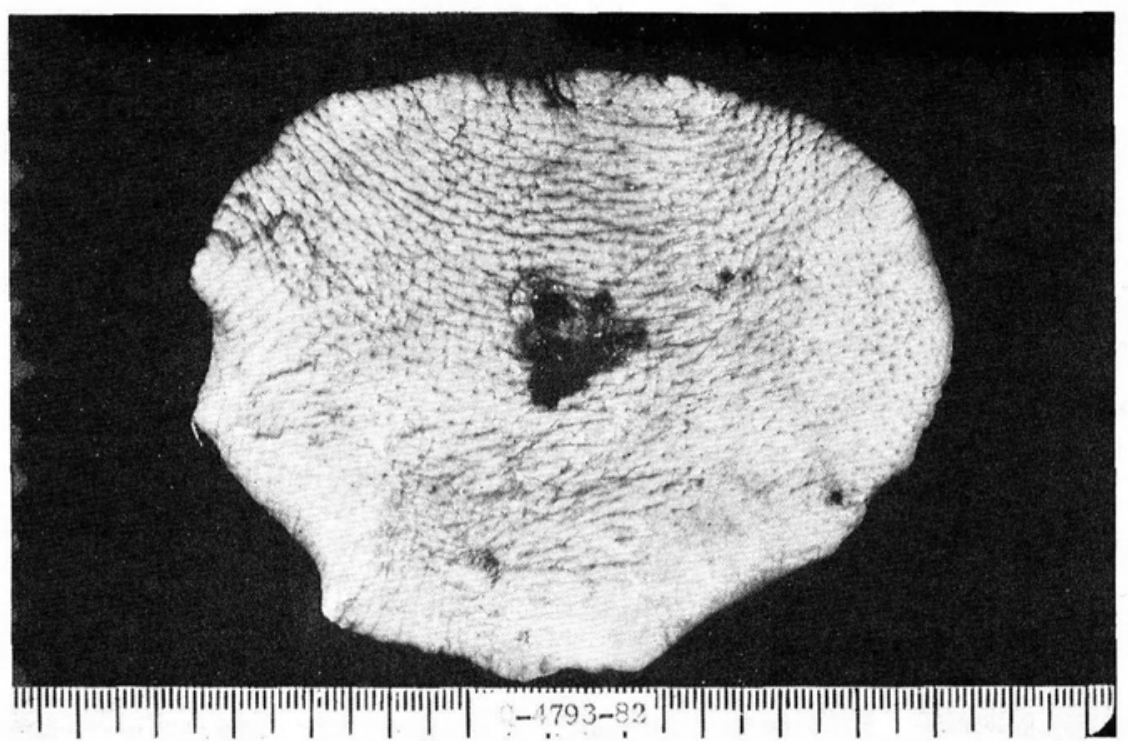

Fig. 32.

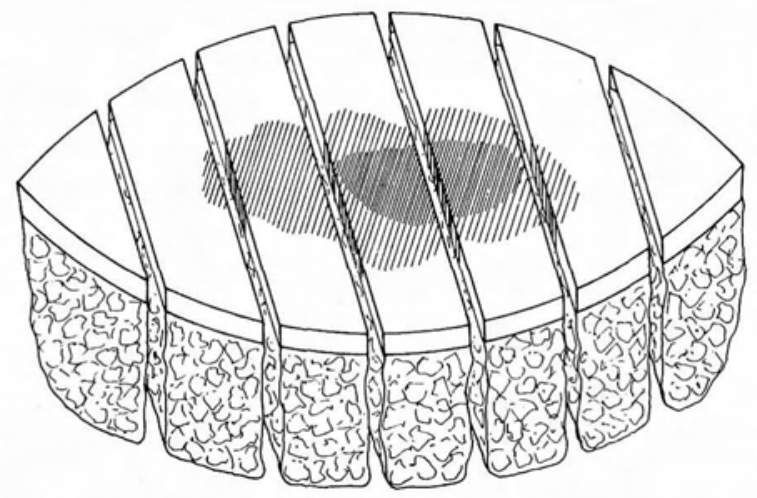

Fig. 33.
Figs. 31-33. Melanoma. Fig. 31: lesión tumoral pigmentada, de borde geográfico y con diferentes tonos de pigmento. Está indicada la resección biopsia, como se ve en la figura 32. Una forma de procesar el especímen quirúrgico en su totalidad se esquematiza en la figura 33. Cada corte es un bloque que lleva la numeración pertinente.
La manera como sea cortado el espécimen y la ubicación correspondiente de cada uno de los cortes deberá ser claramente especificada en la descripción macrocóspica del mismo.

Si el espécimen es grande y presenta gran cantidad de grasa no importante para el diagnóstico, ésta puede quitarse para asegurar una mejor fijación y facilitar el corte $^{(31)}$.

La inclusión exige una correcta orientación del espécimen impregnado en parafina, pues la interpreta- ción histológica depende de la visión correcta del corte que incluya verticalmente la capa córnea, la epidermis, la dermis y la hipodermis, en sus proporciones reales. Los cortes transversales y tangenciales son imposibles de interpretar (Fig. 30).

El técnico que incluya las biopsias de piel debe tener conocimiento sobre los diferentes tipos de biopsias utilizadas, así como sobre la estructura de la piel. Debe tener experiencia para identificar las capas de la piel en el espécimen ya fijado pues como los especímenes son pequeños solo hay una oportunidad para 

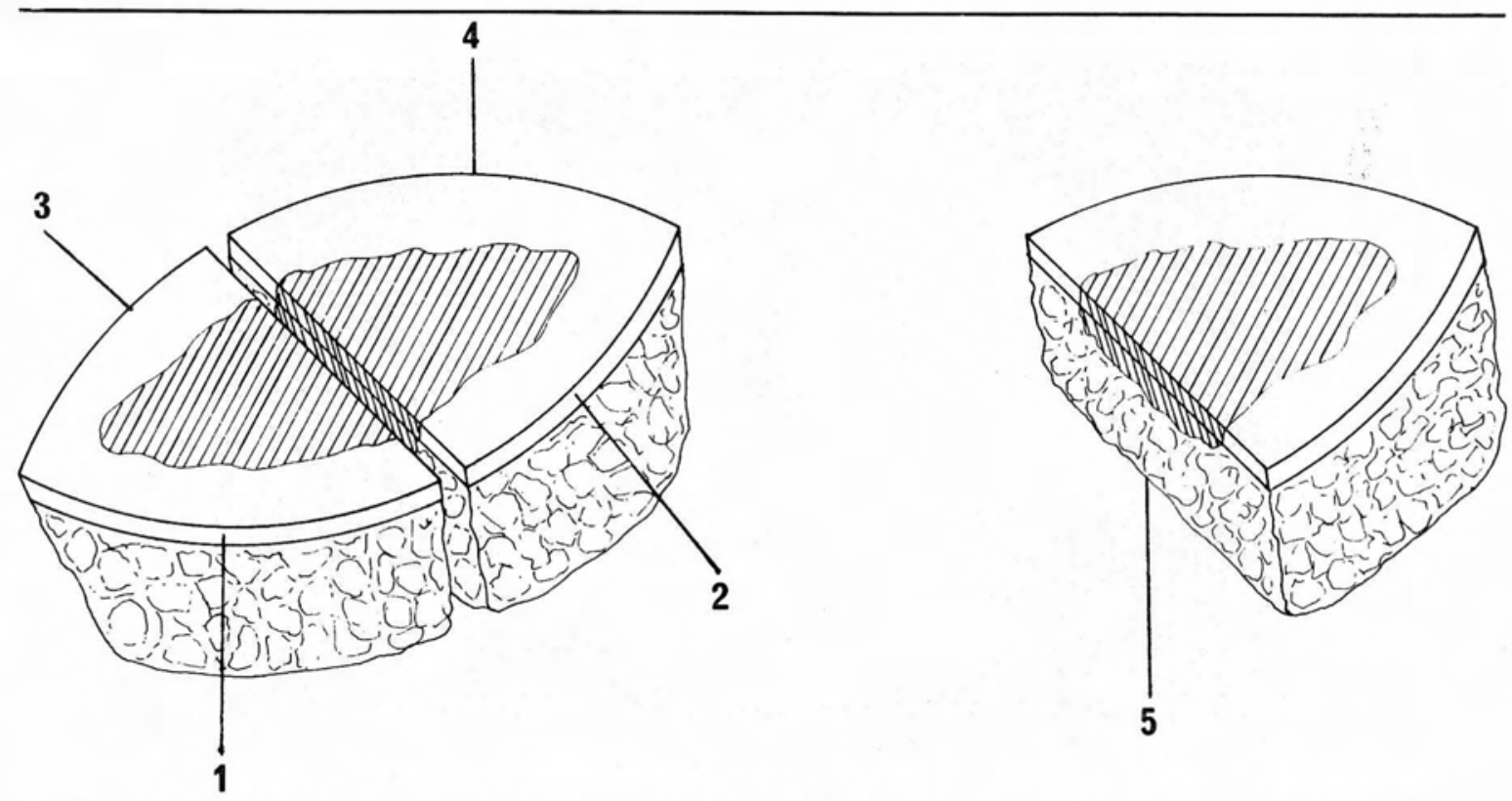

Fig. 34 Esquemas de proceso de especímenes tumorales, principalmente del carcinoma basocelular. En el corte histológico se determina si hay o no tumor en los bordes profundos (5) o laterales de resección (1-4).

hacer la inclusión correcta: de lo contrario, se pueden hacer diagnósticos equivocados con perjuicio para el paciente y con detrimento para el grupo de trabajo.

El bloque se deberá cortar de hipodermis a epider$\mathrm{mis}^{(31)}$ o viceversa ${ }^{(24)}$, pero nunca lateralmente.

La placa debe contener el mayor número posible de cortes seriados. Se recomienda analizar unos 30 cortes por cada biopsia. En instituciones de docencia es aconsejable tener 3 placas por espécimen para proveer un material de estudio adecuado ${ }^{(31)}$. Usualmente con el examen de unos pocos cortes se evidencian los cambios histológicos claves, pero si éstos son dudosos es recomendable practicar siempre los cortes seriados que sean necesarios.

Antes de solicitar una nueva biopsia, el espécimen debe haberse estudiado exhaustivamente con cortes seriados a diferentes niveles.

\section{ANALISIS MICROSCOPICO:}

Las siguientes pautas nos han sido útiles:

1. Evitar conocer la información clínica antes del examen histológico. En nuestra experiencia, los "resi- dentes jóvenes" tienden a ver en la placa el diagnóstico clínico remitido.

2. Contar rápidamente a simple vista el número de cortes y apreciar el tamaño de los mismos en las placas histológicas. Estudiar por lo menos dos láminas con cortes seriados teñidos con HE. La coloración de PAS se practica de rutina en biopsias de cuero cabelludo, pliegues, palmas y plantas; es mandatoria y prioritaria en las biopsias de la uña para detectar dermatofitos (Figs. 26-27). Se hacen otras coloraciones según lo sugiera el estudio de HE. El tricrómico es útil para demostrar nervios o remanentes neurales en las biopsias de lepra.

3. Practicar un análisis microscópico con el objetivo panorámico $(4 \mathrm{x})$. Determinar la naturaleza y localización del proceso: Tumor vs. lesión inflamatoria superficial, profunda o hipodérmica; compromiso o no de los anexos.

4. Deducir el sitio de la biopsia. Determinar un diagnóstico tentativo.

5. Analizar con aumentos mayores todas las capas cutáneas, desde la córnea hasta la hipodermis. Confirmar el diagnóstico tentativo. 
6. Hacer una descripción microscópica global del proceso.

7. Realizar una correlación clínico-patológica.con los datos de la historia.

8. Formular un diagnóstico definitivo, con comentario y nota aclaratoria si fuere necesario, incluyendo posibles diagnósticos diferenciales.

9. No utilizar términos como "dermatitis crónica no específica" y "ver descripción microscópica".

10. Cuando se utilizan términos como: "sugestiva de" y "compatible con", se quiere dar a entender que no hay certeza total en el diagnóstico. Tratamos de utilizarlos la menor cantidad de veces posible y sugerimos al clínico que los tome con la duda razonable que contienen. No abusar de estos términos permite que el clínico no los tome como diagnósticos definitivos.

11. No dudar en comunicarse con el clínico para indagar sobre datos que ayuden a aclarar el diagnóstico.

\section{BIBLIOGRAFIA}

1. Guthrie D. Historia de la Medicina. Barcelona: Salvat Editores, S.A., 1953.

2. King DF, Gustave Simon: The father of dermatopathology. Am J Dermatopathol, 1979; 1: 225.

3. González-Mendoza, A. La biopsia de piel. Patología (Mex), 1984; 22: 291.

4. Ackeman AB. Dermatopathology is for dermatopathologists and pathologists. Am J Dermatopathol. 1983; 5 (2): 107.

5. Sasz Peters M, Winkelman Rk. Symposium on dermatologic surgery. The biopsy. Dermatologic Clinics. 1984; 2 (2): 209.

6. Rodríguez G, Palencia Y. Esporotricosis. Valor diagnóstico del cuerpo asteroide. Biomédica (Bogotá). 1985; 5 (1-2): 41.

7. Kheir SM, et al. Histologic variation in the skin lesions of the glucagonoma syndrome. Am J Surg Pathol, 1986; 10 (7): 445.
8. Anderson PC. Skin biopsy. JAMA, 1967; 201 (10): 136.

9. Caro MR. The pathologists is not infallible in diagnosis of skin lesions. Arch Dermatol. 1962; 85: 80.

10. Pérez-Tamayo R. La biopsia. En: Temas en Patología. Salvat Editores. México. 1975; $\mathrm{p} 73$.

11. Pinckus H. (ed). Dermatopathology, Part I. Cutis. 1977; 20 (5).

12. Pinckus H. (ed). Dermatopathology, Part II. Cutis. 1978; 21 (2).

13. Montgomery $\mathrm{H}$. Value and limitations of biopsy in dermatology. Arch Dermatol. Syphilol. 1938; 38 (3): 329.

14. Ackerman BA. Biobsy: why, where, when, how. J Derm. Surg. 1975; 1 (1): 21.

15. Shapiro L. Dermal biopsy. Med. Clinics, N.A., 1965; 49: 531.

16. Ackerman BA. Histologic diagnosis of inflammatory skin diseases. A Method by pattern analysis. Philadelphia: Lea \& Febiger, 1978.

17. Bart RS, Kopf AW. Techniques of biopsy of cutaneous neoplams. J Dermatol Surg Oncol. 1979; 5: 12.

18. Valenzuela R, et al. Interpretation of immunofluorescence patterns in skin diseases. ASCP, 1984.

18A. Black MM, et al. The value of immunefluorescence techniques in the diagnosis of bullous disorders: A review. Clin. Exp. Dermatol, 1983; 8: 337.

19. Nadji M. Immunoperoxidase techniques. I. Fact and artifacts, Am J Dermatopathol, 1986; 8 (1): 32.

20. Arndt K. Manual of dermatological terapeutics. Boston: Little Brown \& Co. 1979; p. 227.

21. Lamm J, et al. Histologic artifact due to madajet. Arch, Dermatol. 1985; 121: 835.

22. Mehregan AH, Pinckus H. Artifacts in dermal histopathology. Arch. Dermatol. 1966; 94: 218.

23. Carpenter $\mathrm{CL}$, et al. Dermojet histopathological artifacts. Arch. Dermatol. 1965; 92: 301.

24. Mehregan AH, Pinckus' guide to dermatohistopathology. Fourth Edition. Appleton Century Crofts. Prentice-Hall. New York. 1986.

25. Miller MA, Shelley, WB. Antibacterial properties of lidocaine on bacteria isolate from dermal lesions. Arch. Dermatol. 1985; 121: 1157. 
26. Kornberg R, Ackerman AB. Pseudomelanoma. Recurrent melanocytic nevus following partial surgical removal. Arch. Dermatol. 1975; 11: 1588.

27. Baran R. Surgery of the nail. Dermatol. Clinics. 1984; 2 (2): 271.

28. Stone OJ, et al. Biopsy of the nail area. Cutis. 1978; 21: 257.
29. Milne JA. An introduction to the diagnostic histopathology of the skin. Londres: Edward Arnold. 1972; pp.4.

30. Reed RJ. New concepts in surgical pathology of the skin. Hartmann W. Edit. New York: John Wiley \& Sons. 1976.

31. White CR. Laboratory handling of skin biopsy specimens. Lab Med 1982; 13 (4): 211. 


\section{APENDICE \\ FIJADORES USADOS CORRIENTEMENTE \\ EN DERMATOPATOLOGIA}

FORMOL TAMPONADO NEUTRO:

$\begin{array}{lrc}\text { Formalina al 37-40\% } & 100 \mathrm{ml} \\ \text { Agua destilada } & 900 \mathrm{ml} \\ \text { Fosfato sódico monobásico } & 4 \mathrm{~g} . \\ \text { Fosfato sódico dibásico } & 6.5 \mathrm{~g} .\end{array}$

La solución de formaldehído (gas formaldehído en agua, aproximadamente al $40 \%$, llamado formalina) se toma como solución al $100 \%$ cuando se elaboran formoles con otro porcentaje. Ejemplo: $10 \mathrm{ml}$ de formalina $+90 \mathrm{ml}$ de agua $=$ formol al $10 \%$.

\section{FORMOL SALINA}

Formalina al 37-40\%

Cloruro de sodio

Agua corriente

FORMOL AL $10 \%$

Formalina al $37-40 \%$

Agua corriente

$10 \mathrm{ml}$

$90 \mathrm{ml}$

\section{SOLUCION DE BOUIN}

Acido pícrico (solución acuosa saturada) $750 \mathrm{ml}$ Formalina al 37-40\% $\quad 250 \mathrm{ml}$

Acido acético glacial $50 \mathrm{ml}$

\section{FIJADORES PARA MICROSCOPIA ELECTRONICA:}

Glutaraldehído al 3\% en Buffer de fosfato 0.1 M.

Fórmula general:

Glutaraldehído al 25\%

$12 \mathrm{ml}$

Buffer fosfato 0.1 M (pH 7.1 - 7.3)
Preparación de buffer:

$\begin{array}{lll}\text { Solución A } & 28 & \mathrm{cc} \\ \text { Solución B } & 72 & \mathrm{cc}\end{array}$

Preparación de soluciones:

Solución A: uno cualquiera de los siguientes fosfatos.

Fosfato monobásico de sodio $1 \mathrm{H}_{2} \mathrm{O} \quad 27.8 \mathrm{~g} 6$

Fosfato monobásico de sodio $2 \mathrm{H}_{2} \mathrm{O} \quad 31.2 \mathrm{~g}$

Agua destilada $\quad 1.000 \mathrm{cc}$

Solución B: uno cualquiera de los siguientes fosfatos.

Fosfato dibásico de sodio $7 \mathrm{H}_{2} \mathrm{O} \quad 53.65 \mathrm{~g} 6$

Fosfato dibásico de sodio $12 \mathrm{H}_{2} \mathrm{O} \quad 71.0 \mathrm{~g} 6$

Fosfato dibásico de sodio anhidro $\quad 28.4 \mathrm{~g}$

Agua destilada $1.000 \mathrm{cc}$.

Las soluciones amortiguadoras duran varios meses conservadas en la nevera a $4^{\circ} \mathrm{C}$. El fijador se prepara en cantidad suficiente para dos semanas. La fijación del tejido se hace a temperatura ambiente.

FIJADOR DE CARSON: (pH 7 - pH 7.5)

Formalina al $37-40 \%$

Agua destilada

Fosfato monobásico de sodio

Hidróxido de sodio

$400 \mathrm{ml}$
$3.600 \mathrm{ml}$
$74.4 \mathrm{~g}$
$16.6 \mathrm{~g}$

Nota: Adicionar fosfato de sodio monobásico si la solución es ácida, y ácido clorhídrico $0.1 \mathrm{~N}$, si es básica.

Este fijador es útil para microscopía de luz y electrónica. 
CONSERVACION DE MUESTRAS PARA INMUNOFLUORESCENCIA

Solución amortiguada de Mitchel

Fórmula general:

Sulfato de amonio

Puffer de Mitchel
Preparación del buffer:

$\begin{array}{llcc}\text {-Citrato de potasio } & 1 \mathrm{M} & 2.5 \mathrm{ml} \\ \text {-Sulfato de magnesio } & 0,1 \mathrm{M} & 5 & \mathrm{ml} \\ \text {-N-Etilmaleimida } & 0,1 \mathrm{M} & 5 & \mathrm{ml} \\ \text {-Agua destilada } & & 87.5 \mathrm{ml}\end{array}$

Nota: la solución se ajusta a pH 7 con hidróxido de potasio 1M. Esta solución conserva adecuadamente, hasta por dos semanas, las biopsias que vayan a ser sometidas a estudios usuales de inmunofluorescencia. 